\title{
Ligand-regulated oligomerization of $\beta_{2}$-adrenoceptors in a model lipid bilayer
}

This is an open-access article distributed under the terms of the Creative Commons Attribution License, which permits distribution, and reproduction in any medium, provided the original author and source are credited. This license does not permit commercial exploitation without specific permission.

\section{Juan José Fung ${ }^{1}$, Xavier Deupi ${ }^{2}$, Leonardo Pardo', Xiao Jie Yao', Gisselle A Velez-Ruiz ${ }^{3}$, Brian T DeVree ${ }^{3}$ Roger K Sunahara ${ }^{3}$ and Brian K Kobilka',*}

${ }^{1}$ Department of Molecular and Cellular Physiology, Stanford University School of Medicine, Stanford, CA, USA, ${ }^{2}$ Laboratori de Medicina Computacional, Unitat de Bioestadística, Facultat de Medicina, Universitat Autònoma de Barcelona, Barcelona, Spain and ${ }^{3}$ Department of Pharmacology, University of Michigan Medical School, Ann Arbor, MI, USA

The $\beta_{2}$-adrenoceptor $\left(\beta_{2} A R\right)$ was one of the first Family A G protein-coupled receptors (GPCRs) shown to form oligomers in cellular membranes, yet we still know little about the number and arrangement of protomers in oligomers, the influence of ligands on the organization or stability of oligomers, or the requirement for other proteins to promote oligomerization. We used fluorescence resonance energy transfer (FRET) to characterize the oligomerization of purified $\beta_{2} A R$ site-specifically labelled at three different positions with fluorophores and reconstituted into a model lipid bilayer. Our results suggest that the $\beta_{2} A R$ is predominantly tetrameric following reconstitution into phospholipid vesicles. Agonists and antagonists have little effect on the relative orientation of protomers in oligomeric complexes. In contrast, binding of inverse agonists leads to significant increases in FRET efficiencies for most labelling pairs, suggesting that this class of ligand promotes tighter packing of protomers and/or the formation of more complex oligomers by reducing conformational fluctuations in individual protomers. The results provide new structural insights into $\beta_{2} A R$ oligomerization and suggest a possible mechanism for the functional effects of inverse agonists.

The EMBO Journal (2009) 28, 3315-3328. doi:10.1038/

emboj.2009.267; Published online 17 September 2009

Subject Categories: signal transduction

Keywords: $\beta_{2}$-Adrenoceptor; FRET; inverse agonist; oligomers; TM6

\section{Introduction}

The majority of physiological responses to hormones and neurotransmitters are mediated by G protein-coupled receptors (GPCRs). These integral membrane proteins relay signals

\footnotetext{
*Corresponding author. Department of Molecular and Cellular Physiology, Stanford University School of Medicine, Room B157, Beckman Center, 279 Campus Drive, Stanford, CA 94305, USA. Tel.: + 1650723 7069; Fax: + 1650498 5092;

E-mail: kobilka@stanford.edu
}

Received: 16 April 2009; accepted: 18 August 2009; published online: 17 September 2009 elicited by an array of structurally diverse agonists including photons, ions, small organic compounds, peptides, proteins and lipids (Hill, 2006). GPCRs have been classically described as monomeric transmembrane receptors that form a ternary complex: a ligand, the GPCR, and its associated G protein (Chabre and le Maire, 2005; Fung et al, 1981). This classical view is compatible with observations that monomeric rhodopsin and $\beta_{2}$-adrenoceptor $\left(\beta_{2} \mathrm{AR}\right)$ are capable of activating $G$ proteins (Bayburt et al, 2007; Ernst et al, 2007; Whorton et al, 2007). Nevertheless, it is now well accepted that Family C GPCRs are constitutive dimers (Jones, et al, 1998; MargetaMitrovic et al, 2000; Galvez et al, 2001), and many Family A GPCRs have been observed to oligomerize in cells. This was initially shown for the $\beta_{2} \mathrm{AR}$ in 1996 (Hebert et al, 1996), and was later followed by publications demonstrating both homoand hetero-oligomerization of a broad spectrum of Family A GPCRs using a variety of techniques (Jordan and Devi, 1999; Angers et al, 2000; Gines et al, 2000; Rocheville et al, 2000; Cheng and Miller, 2001; Mellado et al, 2001; Latif et al, 2002; Salahpour et al, 2004; Gonzalez-Maeso et al, 2008; Guo et al, 2008; Vilardaga et al, 2008). Despite this evidence, the effect of ligands on formation, organization and stability of receptor oligomers, as well as the role of other cellular proteins, is not well understood and may be receptor subtype specific (Angers et al, 2000; Cheng and Miller, 2001; Latif et al, 2002; Zhu et al, 2002; Roess and Smith, 2003; Law et al, 2005).

High-resolution crystal structures are now available for the inactive state of the $\beta_{2} \mathrm{AR}$ (Cherezov et al, 2007; Rasmussen et al, 2007; Rosenbaum et al, 2007); yet, we still know very little about the structure, stoichiometry and dynamics of oligomers in lipid bilayers. To date, much of what is known about oligomerization of $\beta_{2}$ ARs and other Family A GPCRs comes from elegant studies using intermolecular fluorescence/bioluminescence resonance energy transfer (FRET or BRET) in live cells (Angers et al, 2000; Salahpour et al, 2004; Milligan and Bouvier, 2005). In an effort to complement these cell-based studies and better understand the process of GPCR oligomerization and the organization of protomers within oligomers, we investigated oligomerization of purified $\beta_{2} \mathrm{AR}$ in a model membrane system. By site specifically labelling purified monomeric $\beta_{2} \mathrm{AR}$ and reconstituting it into lipid vesicles, we are able to show that this receptor effectively forms specific multimeric assemblies in lipid bilayers as monitored by FRET and cross-linking studies. FRET saturation studies are most consistent with the formation of tetramers, and differences in FRET between different labelling pairs allow us to propose a model of the orientation of the protomers within the tetramer. An agonist and neutral antagonist have little effect on $\beta_{2} \mathrm{AR}$ oligomerization, but the inverse agonist ICI 118,551 promotes rearrangement of the protomers and/or the formation of higher-order oligomers. 


\section{Results}

\section{Site-specific labelling of purified monomeric $\beta_{2} A R$ and reconstitution into lipid vesicles}

The goal of our studies was to monitor self-association of $\beta_{2} \mathrm{AR}$ following reconstitution in lipid vesicles and to obtain information about the relative orientation of protomers in oligomers. FRET using small-molecular-weight fluorescent probes is an ideal tool for these studies because it provides relative distance information yet requires relatively small amounts of protein (Mansoor et al, 2006). To achieve sitespecific labelling of the $\beta_{2} \mathrm{AR}$, we generated modified receptors having single-reactive cysteines that can be chemically modified with sulphydryl-reactive fluorophores. Mutants were made on a minimal cysteine background in which the five chemically reactive cysteines, out of 13 , were mutated (see section Materials and methods). These mutations have no effect on ligand binding or $\mathrm{G}$ protein coupling. The remaining three cysteines that are not palmitoylated or are part of disulphide bonds are not reactive due to their location in the hydrophobic core (Figure 1A). We initially constructed 18 single-cysteine mutants in the cytoplasmic domains of the receptor. Three were chosen based on their functional properties, chemical reactivity and their distribution (Figure 1B): $\Delta 5$-T66C (intracellular loop-1, ICL1), $\Delta 5$-A265C (transmembrane domain-6, TM6) and $\Delta 5$-R333C (helix-8, H8) (Cherezov et al, 2007; Rasmussen et al, 2007; Rosenbaum et al, 2007). This spatial distribution of the labelling sites was designed to provide information about the orientation of protomers relative to each other.

Modified receptors were expressed in Sf9 cells using recombinant baculovirus and purified using sequential antibody and alprenolol affinity chromatography. We have shown previously that this purification protocol produces monomeric, detergent-solubilized $\beta_{2} \mathrm{AR}$ (Whorton et al, 2007). Purified, detergent-solubilized $\beta_{2} A R$ was labelled with Cy3 or Cy5 maleimide. These fluorophores were chosen for FRET studies because they possess an $\mathrm{R}_{0}$ value (Förster critical distance where $50 \%$ of energy transfer occurs) in the range of 37 to $56 \AA$ depending on the experimental system (Mansoor et al, 2006; Massey et al, 2006). This is ideal for studying receptor-receptor interactions since a monomer has approximate dimensions of $30 \AA \times 40 \AA \times 70 \AA$. $\beta_{2}$ ARs were labelled with stoichiometric amounts of either Cy 3 or Cy5, and the efficiency of labelling was determined by absorption spectroscopy (Supplementary Table I). Labelled $\beta_{2}$ AR was reconstituted into a mixture of 1,2-dioleoyl-sn-glycero-3phosphocholine (DOPC) and cholesterol hemisuccinate (CHS) lipids. Three samples were generated for each experiment: (1) reconstituted Cy3-labelled $\beta_{2} \mathrm{AR}$; (2) reconstituted Cy5-labelled $\beta_{2} \mathrm{AR}$ and (3) Cy3-labelled $\beta_{2} \mathrm{AR}$ mixed with Cy5-labelled $\beta_{2} A R$ and then reconstituted. The final lipid-toreceptor molar ratio (mol-to-mol) was 1000:1 unless otherwise indicated. The same samples were prepared for controls, but were maintained in $0.1 \% \mathrm{DM}$ and not reconstituted into vesicles.

\section{Orientation of $\beta_{2} A R$ in lipid vesicles}

Knowing the orientation of $\beta_{2} \mathrm{AR}$ in our lipid vesicles is essential for interpreting FRET measurements. Random orientation would generate potential non-physiological (antiparallel) oligomers. While random orientation might be expected, previous studies have shown that rhodopsin orients predominantly in one direction following reconstitution (Niu et al, 2002). We used several complementary strategies to determine the orientation of $\beta_{2} \mathrm{AR}$ in phospholipid vesicles (Figure 2A). Factor $\mathrm{Xa}$ is a protease that selectively cleaves the $\beta_{2} \mathrm{AR}$ within the third ICL (ICL3). Receptors oriented inside-out (ICL3 outside of lipid vesicle) will be susceptible to Factor Xa, whereas those oriented outside-out will not (Figure 2A). Approximately $90 \%$ of reconstituted $\beta_{2} \mathrm{AR}$ was
A
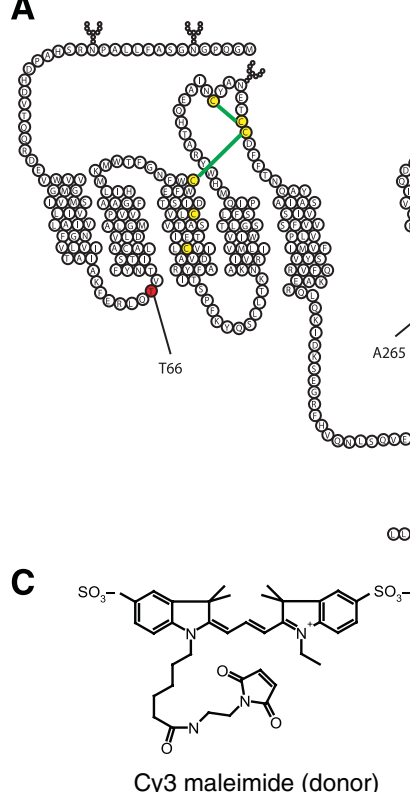

Cy3 maleimide (donor)
B

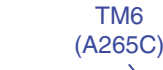
A265C

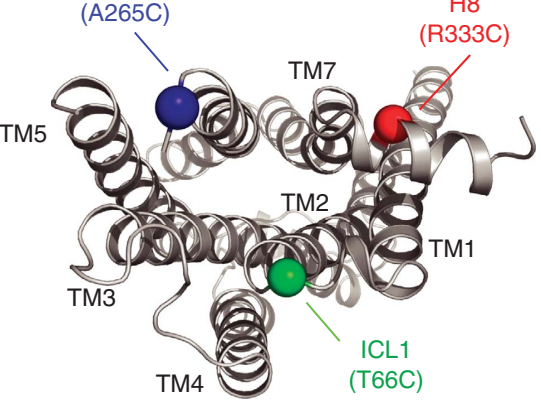

000000000000000

00000000

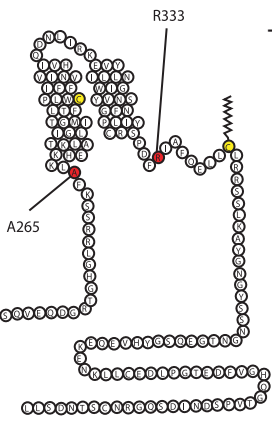

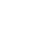

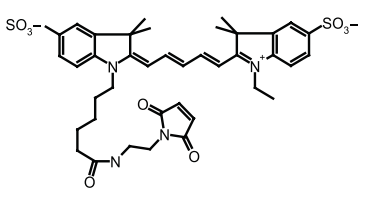

Cy5 maleimide (acceptor)

Figure $1 \beta_{2}$ AR single-cysteine constructs and FRET donor-acceptor pair. (A) Three single-reactive cysteines constructs were generated on a minimal cysteine background $\left(\Delta 5-\beta_{2} A R\right)$. The labelling sites were placed in the first ICL, $\Delta 5-\beta_{2} A R-T 66 C$, at the cytoplasmic end of the sixth transmembrane segment, $\Delta 5-\beta_{2}$ AR-A265C, and helix eight, $\Delta 5-\beta_{2} A R-R 333 C$. (B) Intracellular $3 \mathrm{D}$ view of the distribution of regions chosen for single-cysteine mutants, $\alpha$-carbons are depicted. (C) FRET donor $\left(\lambda_{\text {ex }}=549 \mathrm{~nm} ; \lambda_{\text {em }}=570 \mathrm{~nm}\right)$ and acceptor pair $\left(\lambda_{\text {ex }}=650 \mathrm{~nm} ; \lambda_{\text {em }}=670 \mathrm{~nm}\right)$. 

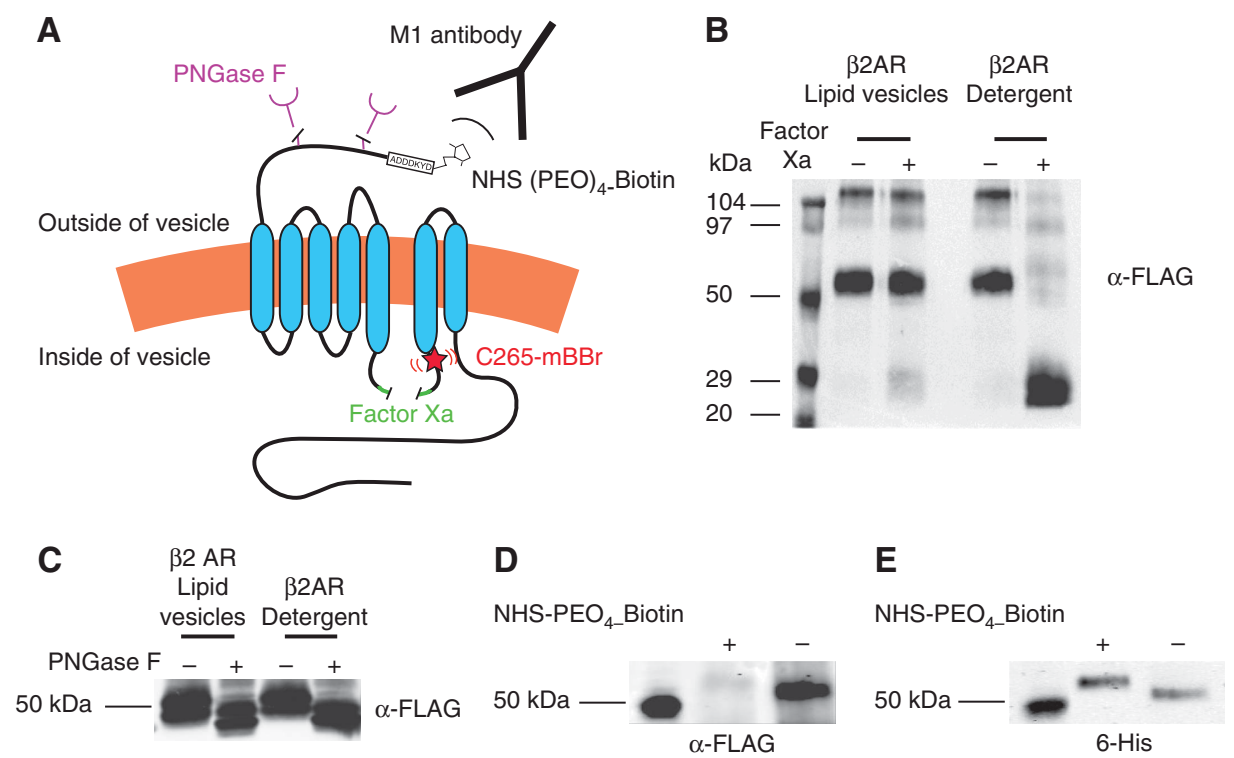

Figure $2 \beta_{2}$ ARs are predominantly oriented outside-out in lipid bilayers. (A) Strategies for determining orientation of $\beta_{2} A R$ in lipid bilayers. (B) Purified receptors were reconstituted as described under Materials and methods and then subjected to treatment with Factor Xa and resolved by $10 \%$ SDS-PAGE and transferred onto nitrocellulose. The presence of $\beta_{2}$ AR was determined by probing with an M1 antibody conjugated with Alexa-680. (C) Samples subjected to PNGase F were prepared and imaged as in panel A. (D, E) Reconstituted samples were treated with the hydrophilic, amine-reactive, alkylating reagent $\mathrm{NHS}_{-} \mathrm{PEO}_{4}$-biotin that disrupts binding of the M1 monoclonal antibody to the FLAG epitope. Samples were assessed for reactivity to M1 antibody (D) and an antibody that recognizes the C-terminal six-histidine tag (E). All data are representative of three independent experiments.

resistant to Factor Xa, whereas all of the receptor was cleaved in the presence of $0.1 \%$ DM (Figure 2B), a concentration of detergent, which permeabilizes the vesicles. These results are consistent with a predominantly outside-out orientation. PNGase $\mathrm{F}$ is an enzyme that cleaves asparaginelinked oligosaccharides on the extracellular N-terminus (Figure 2A). Treatment of reconstituted receptor with PNGase $F$ led to a mobility shift that was indistinguishable from that observed in the presence of $0.1 \% \mathrm{DM}$, consistent with predominantly outside-out orientation (Figure 2C). The orientation was further confirmed using NHS- $\mathrm{PEO}_{4}$-biotin to chemically modify the N-terminus (Figure 2A). This polar compound would not be expected to cross the lipid bilayer. Chemical modification of the N-terminal FLAG epitope results in loss of reactivity to the M1 antibody; treatment of vesicles following reconstitution resulted in the loss of $\mathrm{M} 1$ reactivity for more than $90 \%$ of reconstituted $\beta_{2} \mathrm{AR}$ (Figure $2 \mathrm{D}$ and $\mathrm{E}$ ). Finally, we labelled $\mathrm{A} 265 \mathrm{C}$ on the cytoplasmic side of the $\beta_{2} \mathrm{AR}$ with monobromobimane (mBBr) and examined the ability of tryptophan in solution to quench bimane fluorescence. We observed no quenching of reconstituted, bimanelabelled $\beta_{2}$ AR with $1 \mathrm{mM}$ tryptophan. However, solubilization of vesicles using $0.2 \% \mathrm{DM}$ resulted in significant quenching (Supplementary Figure 1). Taken together, these studies show that the $\beta_{2} \mathrm{AR}$ is predominantly oriented with the extracellular domains on the outside of the vesicle.

\section{Distribution of $\beta_{2} A R$ in lipid vesicles}

In studying oligomerization, it is important to avoid forcing protein together by inhomogeneous reconstitution, that is, trapping the majority of the receptor molecules in a minor population of lipid vesicles. For instance, it has been shown previously that $90 \%$ of rhodopsin molecules were incorporated into only $10 \%$ of vesicles (Mansoor et al, 2006). We used isopycnic density centrifugation to assess the distribu- tion of $\beta_{2}$ ARs in lipid vesicles as previously described for rhodopsin (Mansoor et al, 2006). Cy5-labelled $\beta_{2}$ ARs were reconstituted at a lipid-to-receptor ratio of 1000:1 in lipids containing NBD-phosphocholine (at a final of $0.4 \%$ of total lipid content). This allowed us to analyze samples subjected to a discontinuous sucrose density gradient by following $\mathrm{Cy} 5$ fluorescence (for the presence of $\beta_{2} \mathrm{AR}$ ) and NBD fluorescence (for the presence of lipid vesicles). Our results show nearly perfect correlation between Cy5 fluorescence and NBD fluorescence at every fraction analyzed, suggesting that $\beta_{2} \mathrm{AR}$ molecules are uniformly distributed in these vesicles (Figure 3A). Similar results were obtained with $\beta_{2}$ AR reconstituted at a 10000:1 lipid-to-receptor ratio (Supplementary Figure 2).

To assess the density of $\beta_{2}$ ARs in the lipid vesicles, we used electron microscopy to determine the average diameter of our $\beta_{2}$ AR-containing lipid vesicle preparations. Using a negative staining protocol, we determined that the average diameter of our vesicle preparations at a lipid-to-receptor ratio of 1000:1 was $83 \mathrm{~nm} \pm 12 \mathrm{~nm}$ (Figure $3 \mathrm{~B}$ ). Using the calculations detailed in the Supplementary Materials and methods section, we concluded that there are 50-60 $\beta_{2}$ ARs per lipid vesicle, with the majority oriented in an outside-out manner.

\section{Functional characterization of $\beta_{2} A R$ in lipid vesicles}

We performed saturation binding on purified, reconstituted receptor to determine the affinity of all three single-cysteine mutants for the antagonist $\left[{ }^{3} \mathrm{H}\right]$-dihydroalprenolol (DHA). We observed no significant difference between the three modified $\beta_{2}$ ARs and wild-type $\beta_{2}$ ARs (Table I and Supplementary Figure 3). Competition binding studies with $\left[{ }^{3} \mathrm{H}\right]$-DHA were used to determine the $K_{\mathrm{i}}$ values for the agonist isoproterenol (Iso) and the inverse agonist ICI 118,551 (ICI). As shown in Table I and Figure 4, the values for the single-cysteine mutants are comparable to those obtained for wild-type 


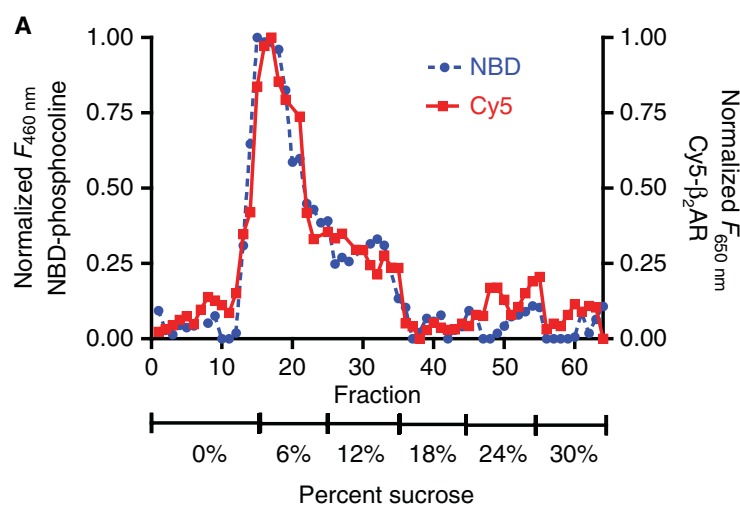

B

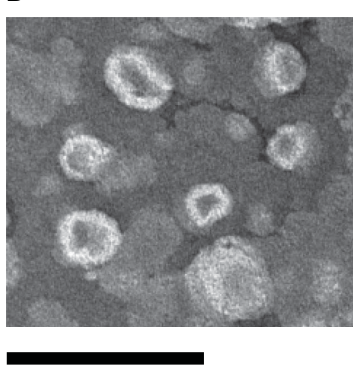

Figure $3 \beta_{2}$ ARs are homogenously distributed in lipid vesicles. (A) To determine the distribution of $\beta_{2}$ ARs in lipid vesicles, sucrose density gradients of samples containing $0.4 \%$ NBD-phosphocholine and Cy5- $\beta_{2} A R s$ reconstituted at a lipid-to-receptor ratio of 1000:1 were performed as described in the Supplementary data. Detection of lipid fractions was performed by following NBD fluorescence $\left(\lambda_{\mathrm{ex}}=460 \mathrm{~nm}\right)$ and receptor fractions by following Cy5 fluorescence $\left(\lambda_{\mathrm{ex}}=649 \mathrm{~nm}\right)$. (B) Reconstituted $\beta_{2}$ ARs were imaged using a negative staining protocol as described in the Supplementary data to determine the size distribution of vesicles and the number of receptors per vesicle. Scale bar length represents $200 \mathrm{~nm}$. Data are representative of three independent experiments.

Table I Agonist, antagonist and inverse agonist binding properties for the single-reactive cysteine receptors ${ }^{\mathrm{a}}$

\begin{tabular}{lccc}
\hline$\beta_{2} \mathrm{AR}$ & \multicolumn{2}{c}{$K_{\mathrm{i}}$ [s.e. interval] (nM) } & $K_{\mathrm{d}} \pm$ s.e.m. \\
\cline { 2 - 3 } Mutant & (-)-Isoproterenol & ICI 118,551 & {$\left[{ }^{3} \mathrm{H}-\mathrm{DHA}\right]$} \\
\hline Wild type & $355[203-620]$ & $1.17[0.77-1.77]$ & $1.3 \pm 0.16$ \\
$\Delta 5$-T66C & $388[319-473]$ & $2.09[1.86-2.35]$ & $1.8 \pm 0.21$ \\
$\Delta 5-\mathrm{A} 265 \mathrm{C}$ & $298[255-348]$ & $1.84[1.45-2.33]$ & $2.5 \pm 0.23$ \\
$\Delta 5$-R333C & $214[168-273]$ & $1.90[1.59-2.27]$ & $2.4 \pm 0.24$ \\
\hline
\end{tabular}

${ }^{\mathrm{a}}$ Saturation and competition binding were performed as described under Materials and methods. Data represent the mean \pm s.e.m. of at least three independent experiments.

$\beta_{2} A R$, suggesting that introduction of the single-reactive cysteines and reconstitution of purified $\beta_{2} \mathrm{AR}$ into lipid vesicles does not alter the pharmacology of the receptor.

Functionality for $\mathrm{G}$ protein coupling of the three singlecysteine mutants was addressed by $\left[{ }^{35} \mathrm{~S}\right]-\mathrm{GTP} \gamma \mathrm{S}$ binding. This assay involves reconstituting purified $\beta_{2} A R$ with purified Tet- $\mathrm{G}_{\alpha \mathrm{s}}$ as previously described (Swaminath et al, 2005; Granier et al, 2007). Agonist binding to all three $\beta_{2} \mathrm{AR}$ single-cysteine mutants led to significant stimulation of $G$ protein coupling that was similar to wild-type receptor (Figure 4C). Treatment of samples with the inverse agonist ICI led to decreases in basal activity similar to that observed for wild-type receptor (Figure 4C). Modification of the single cysteines with Cy5-maleimide fluorophore had no significant effect on $\mathrm{G}$ protein coupling (Figure 4C; $P>0.05$ ).

\section{FRET analysis of fluorophore-labelled $\beta_{2}$ ARs in lipid bilayers}

We first determined FRET between receptors labelled at the same position. $\Delta 5$-A265C labelled with Cy3 was reconstituted with an equivalent amount of $\Delta 5$-A265C labelled with Cy5 in order to monitor TM6/TM6 interactions. This was repeated for $\Delta 5$-T66C and $\Delta 5$-R333C, as reporters for ICL1/ICL1 and H8/H8 interactions, respectively. Figure 5A shows an example of a typical experiment performed on $\Delta 5$-T66C. FRET between Cy3- and Cy5-labelled receptors $(30.3 \pm 1.2 \%)$ is only observed after receptor reconstitution into a lipid bilayer, but not when receptors remain solubilized in detergent
(Figure 5A and Table II). Similar observations were made for Cy3- and Cy5-labelled $\Delta 5$-A265C $(16.7 \pm 1.3 \%)$ and for Cy3and Cy5-labelled $\Delta 5$-R333C (26.9 $\pm 0.8 \%$; Table II).

To provide additional information about the relative orientation of $\beta_{2}$ AR protomers, we investigated FRET between different labelling sites. For example, $\Delta 5$-T66C labelled with $\mathrm{Cy} 3$ was reconstituted with an equivalent amount of $\Delta 5$-A265C labelled with Cy5 in order to examine ICL1/TM6 interactions. The same approach was followed for the other possible combinations, ICL1/H8 and TM6/H8 (Table II). The observation of different FRET efficiencies for different labelling pairs suggests a specific arrangement of receptors in the lipid bilayers rather than nonspecific aggregation. To further rule out the possibility that the FRET observed in these studies is simply due to crowding of labelled receptors at the lipid bilayer, a 10-fold higher molar concentration of lipids (a final lipid-to-receptor ratio of 10000:1) was used in order to reduce the number of receptors per unit area of lipid bilayer. FRET efficiencies observed at a lipid-to-receptor ratio of 10000:1 were not significantly different from those obtained at a ratio of 1000:1 (Figure 5B-D; $P>0.05$ ).

\section{FRET saturation of fluorophore-labelled $\beta_{2} A R$ oligomers}

To further investigate the specificity of the observed oligomerization, as well as the stoichiometry of the oligomers, we performed FRET saturation experiments where the ratio of acceptor fluorophore (Cy5-labelled $\beta_{2} \mathrm{AR}$ ) to donor fluorophore (Cy3-labelled $\beta_{2} \mathrm{AR}$ ) is increased, while maintaining the overall receptor concentration and lipid-to-receptor ratio constant. If the energy transfer is due to specific receptorreceptor interactions, FRET efficiency will saturate as the $\mathrm{Cy} 5 / \mathrm{Cy} 3$ ratio is increased. In contrast, random collisions should yield a quasi-linear relationship (Mercier et al, 2002; James et al, 2006; Harikumar et al, 2008). We observe FRET saturation for all three $\beta_{2} \mathrm{AR}$ labelling sites (Figure $6 \mathrm{~A}-\mathrm{C}$ ), demonstrating the specific nature of the interactions.

In addition, FRET saturation can provide insight into the number of protomers per oligomer. Our FRET saturation results were compared with a well described mathematical model (Veatch and Stryer, 1977; Mercier et al, 2002; James et al, 2006; Harikumar et al, 2008; Harding et al, 2009) that 

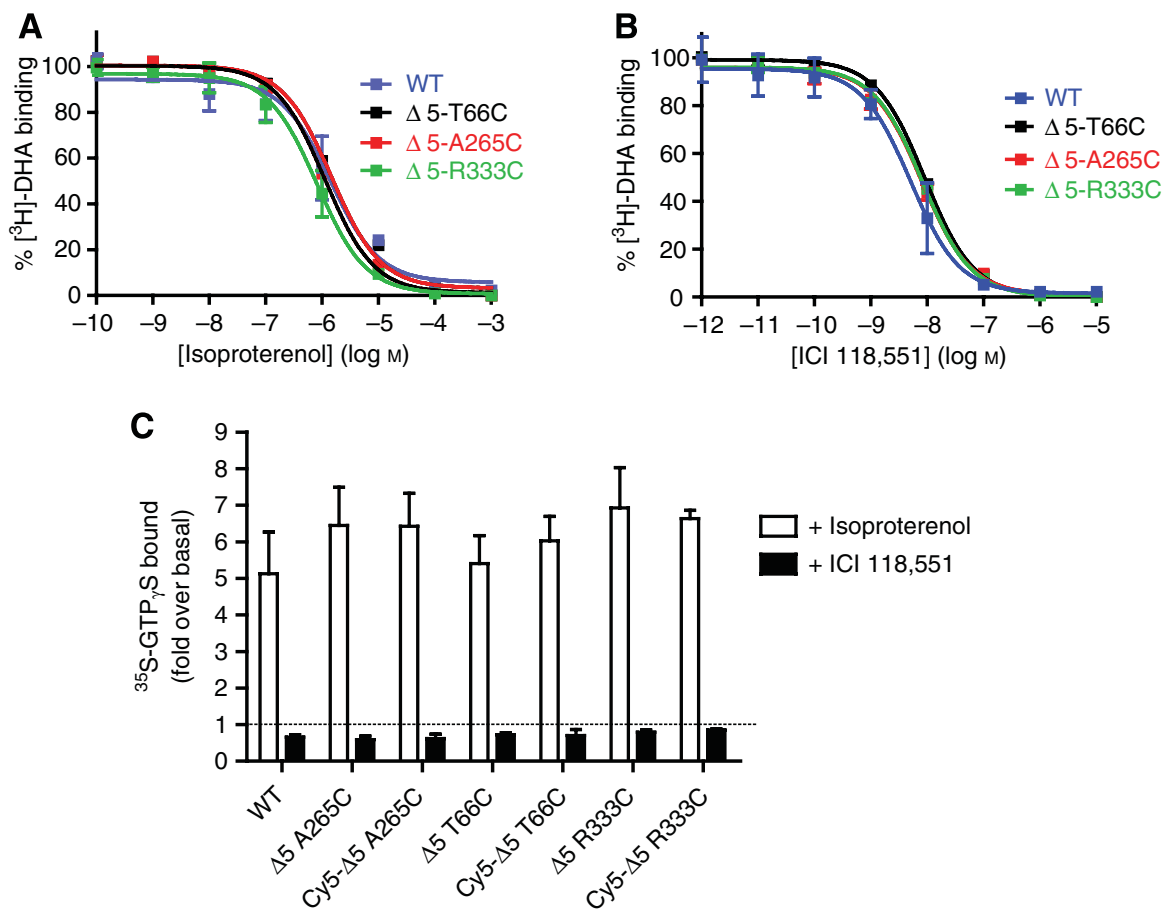

Figure 4 Single-reactive cysteine mutants are fully functional. The affinity of the agonist isoproterenol (A) and the inverse agonist ICI 118,551 (B) was measured for all three single-cysteine mutants ( $\Delta 5$-T66C, $\Delta 5$-A265C and $\Delta 5$-R333C) and wild-type receptor by competitive binding of $\left[{ }^{3} \mathrm{H}\right]$-DHA. Results are expressed as percent of radio-ligand bound in the absence of competitor. (C) Functionality of the three single-cysteine mutants, unlabelled or labelled with Cy5, and wild-type receptor was determined by GTP $\gamma \mathrm{S}$ binding as described in the Supplementary data. $\left[{ }^{35} \mathrm{~S}\right]$-GTP $\gamma \mathrm{S}$-specific binding induced by $10 \mu \mathrm{m}$ isoproterenol (agonist response) or by $10 \mu \mathrm{M}$ ICI 118,551 (inverse agonist response) is shown as fold over basal. All functional data represent the mean \pm s.e.m. of three independent experiments performed in triplicate.

A

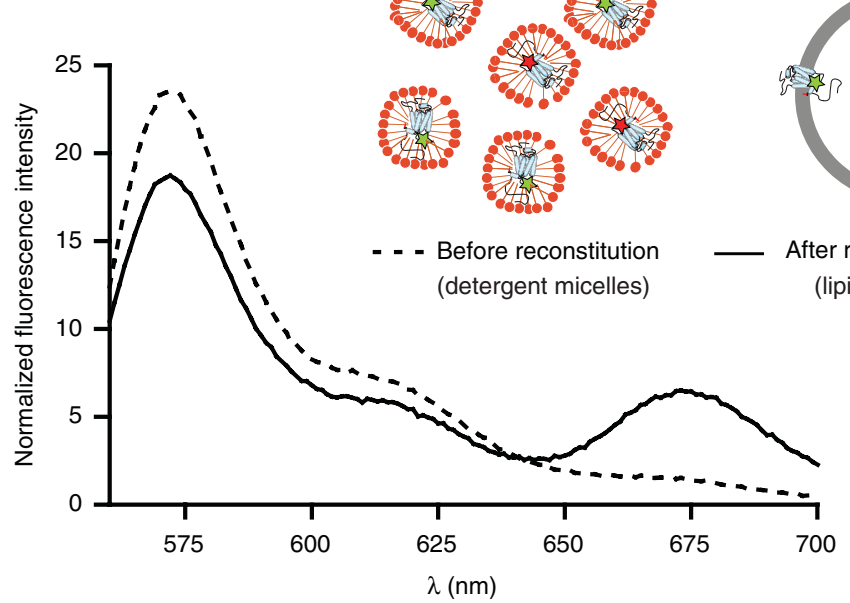

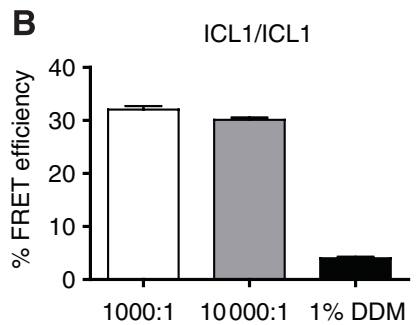

C

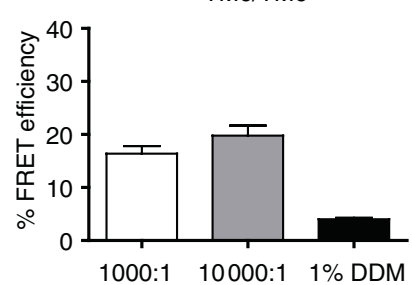

D

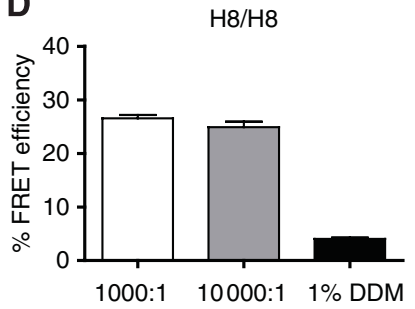

Figure 5 Intermolecular FRET between Cy3- and Cy5-labelled $\beta_{2} A R$ is independent of other cellular proteins and is specific. (A) Purified, detergent-solubilized receptor protein was labelled with Cy3 or Cy5 maleimide and unreacted fluorophore was quenched with cysteine and separated from protein by gel filtration as described under Materials and methods. Cy3- and Cy5-labelled protein samples were mixed at a 1:1 molar ratio and reconstituted into phospholipids bilayers or maintained in detergent. Subtraction of the proper controls and normalization of the raw traces is described in the Supplementary data. Labelled $\beta_{2}$ ARs were reconstituted at a 10-fold higher lipid-to-receptor ratio (10 000:1) and FRET efficiency was measured for ICL1/ICL1 (B), TM6/TM6 (C) and H8/H8 (D) interactions. Data are representative of at least three independent experiments $(\mathrm{A})$ or represent the mean \pm s.e.m. of at least three independent experiments $(\mathrm{B}-\mathrm{D})$. 
Table II FRET efficiencies in the absence of ligand and upon binding of agonist, neutral antagonist or inverse agonist ${ }^{\mathrm{a}}$

\begin{tabular}{|c|c|c|c|c|c|c|c|}
\hline$\beta_{2} \mathrm{AR}$ region & No ligand \pm s.e.m. & + Isoproterenol \pm s.e.m. & $P$-value & + Alprenolol \pm s.e.m. & $P$-value & + ICI $118,551 \pm$ s.e.m. & $P$-value \\
\hline ICL-1/ICL-1 & $30.26 \pm 1.2$ & $31.43 \pm 0.4$ & 0.45 & $29.72 \pm 4.1$ & 0.86 & $34.86 \pm 1.4$ & $0.043^{*}$ \\
\hline TM-6/TM-6 & $16.73 \pm 1.3$ & $17.71 \pm 2.1$ & 0.64 & $21.48 \pm 0.8$ & 0.23 & $27.67 \pm 2.0$ & $0.005^{* *}$ \\
\hline $\mathrm{H}-8 / \mathrm{H}-8$ & $26.85 \pm 0.8$ & $29.56 \pm 1.1$ & 0.06 & $31.40 \pm 3.5$ & 0.07 & $28.33 \pm 1.8$ & 0.418 \\
\hline ICL-1/TM-6 & $24.58 \pm 2.3$ & $22.26 \pm 0.4$ & 0.56 & $27.82 \pm 6.1$ & 0.54 & $30.00 \pm 4.6$ & 0.269 \\
\hline ICL-1/H-8 & $24.08 \pm 1.6$ & $23.71 \pm 0.7$ & 0.91 & $26.87 \pm 4.8$ & 0.49 & $35.33 \pm 2.4$ & $0.006^{* *}$ \\
\hline TM-6/H-8 & $30.98 \pm 0.7$ & $35.27 \pm 1.5$ & $0.01 *$ & $33.63 \pm 0.2$ & $0.05^{*}$ & $25.33 \pm 2.0$ & $0.005^{* *}$ \\
\hline
\end{tabular}

${ }^{\mathrm{a}}$ FRET efficiencies were calculated as described under Materials and methods. Data represent the mean \pm s.e.m. of at least three independent experiments. P-values refer to statistical comparisons between no ligand and three different ligands: isoproterenol, alprenolol and ICI 118,551. ${ }^{*} P<0.05 ;{ }^{* *} P<0.005$.

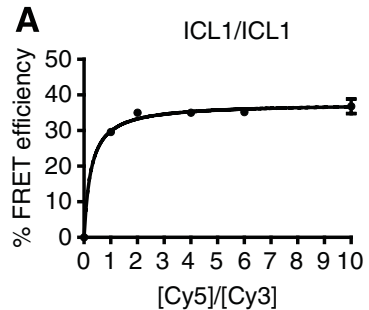

$[$ Су5]/[Су3]

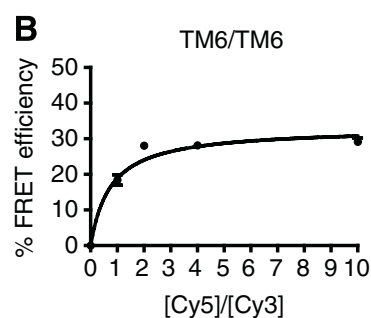

$[\mathrm{Cy} 5] /[\mathrm{Cy} 3]$

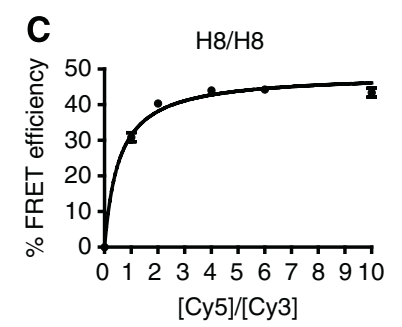

$[$ [Cy5]/[Cy3]

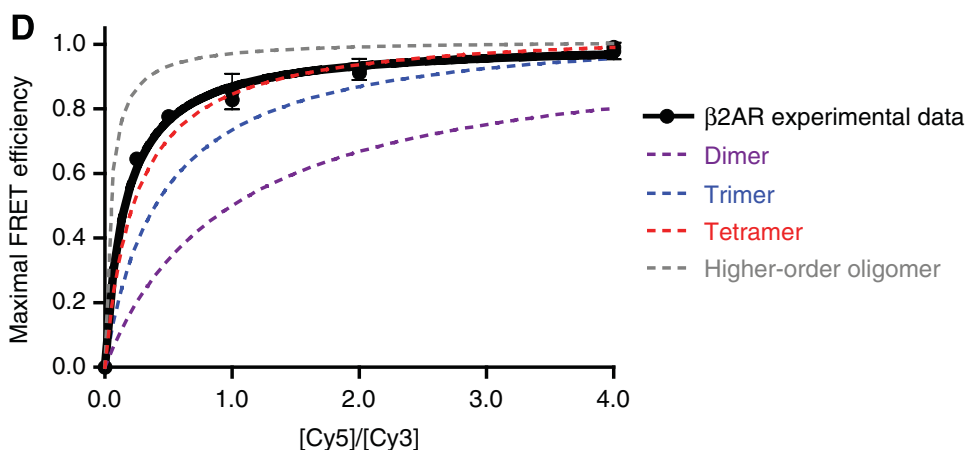

Figure 6 Specificity of $\beta_{2}$ AR oligomerization as assessed by FRET saturation. FRET saturation involved varying the ratio of Cy5- to Cy3-labelled $\beta_{2}$ ARs over a range of 1:1 to 10:1 (Cy5:Cy3), while the overall $\beta_{2}$ AR concentration was kept constant. Saturable FRET is observed for ICL1/ICL1 (A), TM6/TM6 (B) and H8/H8 (C). FRET measurements were performed and calculated as described in the Supplementary data. Data represent the mean \pm s.e.m. of at least three independent experiments. (D) FRET saturation data from all three constructs (A-C above) was normalized to maximal FRET efficiency and then averaged and plotted together with theoretical curves (dashed lines) for dimer, trimer, tetramer and higherorder oligomer that were generated using equation (1) in the Supplementary data.

has been used to predict the maximal energy transfer expected in energy transfer saturation experiments (FRET or BRET) for dimers, trimers, tetramers, etc. It follows that saturation will occur at a lower acceptor/donor ratio for higher-order oligomers than for simple dimers. We normalized our FRET saturation data for all three constructs and compared them with models for dimers, trimers, tetramers and higher-order oligomers (eight protomers), and found that our data are superimposed on the theoretical curve for tetramers (Figure 6D).

\section{The effect of ligand efficacy on $\beta_{2} A R$ oligomerization}

We examined the effects of three classes of GPCR drugs: a full agonist (isoproterenol), a neutral antagonist (alprenolol) and an inverse agonist (ICI) on FRET efficiency between different labelling sites. Upon treatment with saturating amounts $(10 \mu \mathrm{M})$ of the full agonist isoproterenol, a small, but significant, increase in FRET was observed between TM6 and H8 (Figure 7A and Table II; $P<0.05$ ). At saturating concentrations $(500 \mathrm{nM})$, alprenolol produced a similar result between TM6 and H8 (Figure $7 \mathrm{~A}$ and Table II; $P<0.05$ ). It is not possible to say if these small changes are due to subtle changes in the relative arrangement of protomers, or small conformational changes in the receptor.

In contrast to the small changes observed with the agonist and neutral antagonist, much larger changes were observed following exposure to the inverse agonist ICI (Figure 7A and Table II). Inverse agonists include many compounds that were originally classified as antagonists, ligands that occupy the orthosteric binding site, but do not alter receptor function. Instead, inverse agonists inhibit basal agonist-independent activity exhibited by many GPCRs, including the $\beta_{2} \mathrm{AR}$ (Galandrin and Bouvier, 2006). Interestingly, at a saturating concentration ( $500 \mathrm{nM})$ of ICI, significant changes in FRET efficiency were observed for four of the six labelling pairs (Figure 7A and Table II). The ICI-induced changes in FRET reach a maximum at $10 \mathrm{~min}$ (Supplementary Figure 4).

The changes in FRET observed with ICI could reflect changes in the orientation of protomers or the number of protomers in the oligomeric complex. However, these changes could also be due to ligand-induced changes in the 


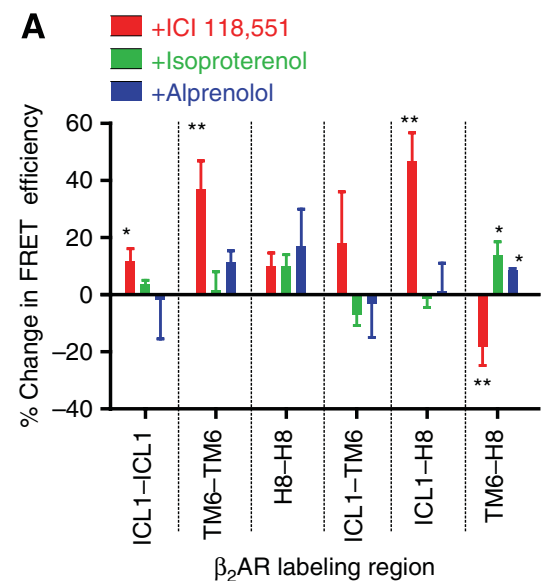

C

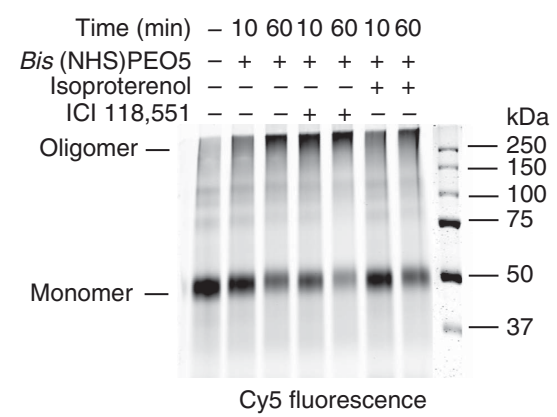

B

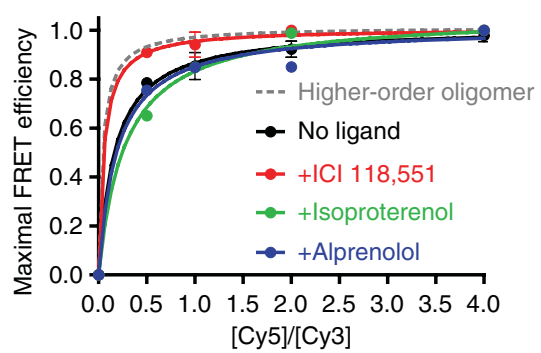

D

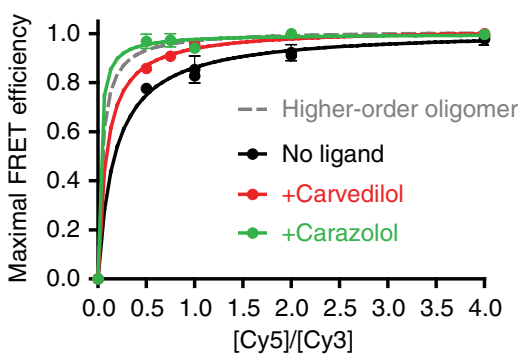

Figure $7 \quad \beta_{2} \mathrm{AR}$ oligomers are regulated by inverse agonists. (A) Treatment of FRET samples with saturating amounts of the inverse agonist ICI 118,551, agonist isoproterenol and neutral antagonist alprenolol. (B) FRET saturation in the presence of ligands. Isoproterenol and alprenolol led to no observable difference from the unliganded FRET saturation curve, whereas ICI 118,551 yielded to a curve that is more consistent with higher-order oligomers. (C) Cross-linking of reconstituted Cy5-labelled $\beta_{2}$ AR samples in the presence or absence of isoproterenol or ICI 118,551 was carried out as described in the Supplementary data. (D) FRET saturation in the presence of the inverse agonists carvedilol (red) and carazolol (green). All data are reported as mean \pm s.e.m. (A, B, D) or are representative of at least three independent experiments (C). ${ }^{*}(P<0.05)$ and ${ }^{* *}(P<0.005)$.

conformation of receptors that influence the mobility of the fluorophore or the polarity of its environment. We, therefore, examined the effect of isoproterenol and ICI on the intensity of the fluorescence and on the anisotropy of the fluorophores in labelled receptors. For both Cy3- and Cy5-labelled $\beta_{2} \mathrm{AR}$ reconstituted individually, treatment with either isoproterenol or ICI did not induce significant changes in the intensity of the fluorescence (data not shown) or anisotropy of the fluorophores, suggesting that the change in FRET efficiencies observed upon ICI treatment are not a result of conformational changes in protomers (Supplementary Figure 5).

The ICI-induced changes in FRET efficiency may be attributed to several additional factors: reorientation of protomers in the oligomers, a tighter packing of the protomers, an increase in the temporal stability of the oligomers (assuming there is an equilibrium between monomers and oligomers), and an increase in the stoichiometry of the oligomeric state (e.g., going from dimers or tetramers to higher-order oligomers). To distinguish between these possibilities, we performed FRET saturation in the presence and absence of ICI, alprenolol or isoproterenol. Samples were incubated with ligands for $30 \mathrm{~min}$ at room temperature and measurements were taken. Results show that in the presence of ICI the saturation curve is more similar to a model for higher-order oligomers, while alprenolol and isoproterenol appear to have no effect on the apparent oligomeric state of the receptor (Figure 7B). Higher-order oligomerization was also observed for the inverse agonists carazolol and carvedilol (Figure 7D)

Cross-linking was used to further address the state of multimeric assembly of the $\beta_{2} \mathrm{AR}$. We used $\mathrm{Bis}(\mathrm{NHS}) \mathrm{PEO}_{5}$, a homobifunctional cross-linker with a spacer length of $21.7 \AA$ that covalently modifies $\varepsilon$-amines of lysine residues and $\alpha$-amine groups at the $\mathrm{N}$-termini, effectively trapping receptors that come within interacting distances. Although concerns have been raised about the potential for crosslinkers to trap transiently interacting proteins (Brett and Findlay, 1979; Downer, 1985; Medina et al, 2004), it is evident that pre-incubation of samples with ICI leads to more extensive cross-linking and trapping of higher-order oligomers of reconstituted $\beta_{2} \mathrm{AR}$ when compared with the unliganded, the agonist and the antagonist treated samples (Figure 7C and Supplementary Figure 6). Taken together, these results suggest that the $\beta_{2} A R$ forms higher-order oligomers in the presence of the inverse agonists ICI, carazolol and carvedilol.

To investigate the effect of ICI on the stability of interactions between protomers, we monitored FRET following addition of $0.2 \%$ DDM, a concentration of detergent that solubilizes the vesicles. We found that the decline in FRET following the addition of detergent was slower and less complete in samples pre-incubated with ICI compared with unliganded samples (Supplementary Figure $7, P<0.05$ ), providing evidence that ICI also stabilizes interactions between protomers. 


\section{The effect of Gs on $\beta_{2} A R$ oligomerization}

To investigate the effect of $G$ protein coupling on oligomerization, we performed FRET saturation experiments by reconstituting $\beta_{2} \mathrm{AR}$ with a three-fold molar excess of purified Gs heterotrimer (Figure 8). This concentration of $G$ protein was chosen to ensure that sufficient $G$ protein would be incorporated into vesicles while having a minimal effect on the reconstitution. The inclusion of Gs did not alter the orientation of the $\beta_{2} \mathrm{AR}$ as determined by the susceptibility to PNGase $\mathrm{F}$ (Figure $8 \mathrm{~A}$ ). We observed a statistically significant $(P<0.008)$ decrease in FRET saturation in the presence of $\mathrm{Gs}$ as compared with reconstitutions in the absence of Gs (Figure $8 \mathrm{~B}$ ) for $\mathrm{Cy} 5 / \mathrm{Cy} 3$ of $0.25,0.5$ and 1 . To determine whether the effect of Gs on FRET saturation was due to

A

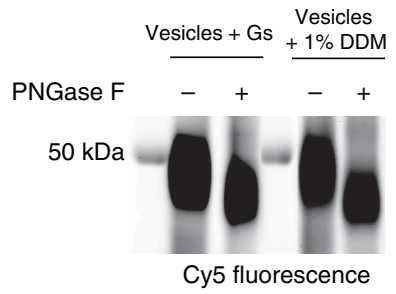

B

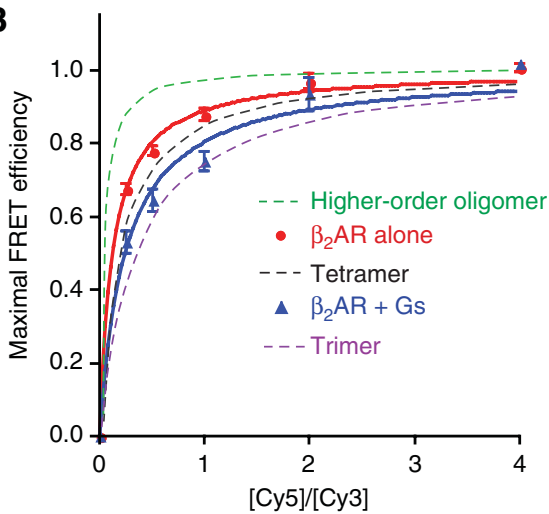

C

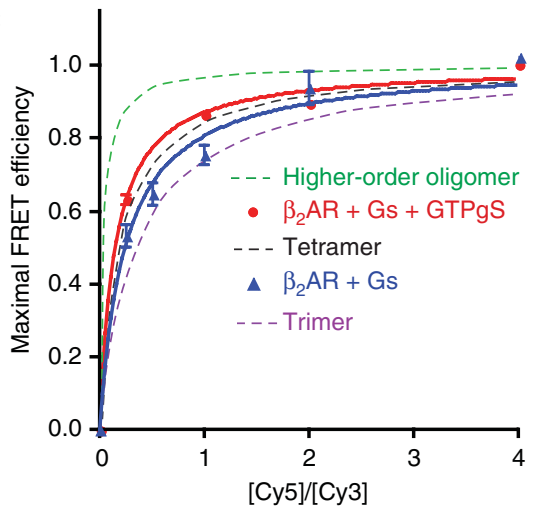

D

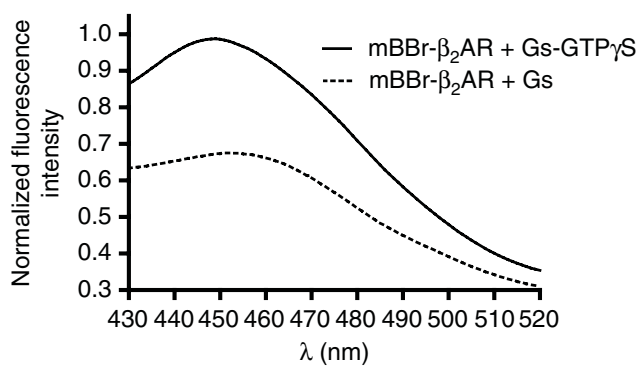

nonspecific effects of reconstituting with another membrane-associated protein, we performed FRET saturation of $\beta_{2} \mathrm{AR}$ in the presence of Gs and GTP $\gamma \mathrm{S}$, which uncouples $\beta_{2} \mathrm{AR}$ and Gs. As shown in Figure 8C, the presence of GTP $\gamma \mathrm{S}$ increases, in a statistically significant manner $(P<0.04)$, FRET saturation to the values observed for $\beta_{2} A R$ alone. To estimate the fraction of $\beta_{2} \mathrm{AR}$ that couples to Gs under these reconstitution conditions, we labelled C265 at the cytoplasmic end of TM6 with $\mathrm{mBBr}$, an environmentally sensitive fluorescent probe. We previously showed that maximal coupling of Gs to $\beta_{2}$ AR reconstituted into HDL particles results in a decrease in the fluorescence intensity and an 18 -nm shift in the maximal emission wavelength $\left(\lambda_{\mathrm{MAX}}\right)$ of $\mathrm{mBBr}-\beta_{2} \mathrm{AR}$ (mBBr- $\beta_{2} \mathrm{AR}$; Yao et al, 2009). As shown in Figure $8 \mathrm{D}$, under reconstitution conditions used for FRET saturation experiments, Gs induced a decrease in intensity and a 4 -nm shift in $\lambda_{\mathrm{MAX}}$ of $\mathrm{mBBr}-\beta_{2} \mathrm{AR}$ relative to the same reconstitution in the presence of GTP $\gamma \mathrm{S}$. Based on the shift of $\lambda_{\text {MAX }}$ we estimate that approximately $20 \%$ of the reconstituted $\beta_{2} \mathrm{AR}$ is coupled to Gs.

\section{Discussion}

Receptor dimerization plays an essential role in the function of Family C GPCRs (Margeta-Mitrovic et al, 2000; Pin et al, 2005). However, the role of oligomerization for Family A (rhodopsin-like) GPCRs is less clear. It has been shown that monomeric rhodopsin and $\beta_{2} \mathrm{AR}$ can activate their respective G proteins (Bayburt et al, 2007; Ernst et al, 2007; Whorton et al, 2007). Yet, there is convincing evidence from a variety of experimental approaches that the $\beta_{2} \mathrm{AR}$ and many other Family A GPCRs exist as dimers or oligomers in the plasma membrane. Most compelling are studies that apply FRET and/ or BRET technology to receptors tagged with fluorescent proteins and expressed in cultured cells (Angers et al, 2000; Mercier et al, 2002; Milligan and Bouvier, 2005; Guo et al, 2008), as well as studies using disulphide cross-linking to trap interactions in cell membranes to map the interface between protomers (Guo et al, 2003, 2005, 2008; Klco et al, 2003). Characterization of the structure (protomer organization) and dynamics of GPCR oligomers is challenging and will

Figure 8 Effect of the G protein Gs on FRET saturation of Cy5- and Cy3-labelled $\beta_{2}$ AR. FRET saturation was performed by varying the ratio of Cy5- to Cy3-labelled $\beta_{2} A R-R 333 C$ over a range of 1:4 to 4:1 (Cy5:Cy3), while the overall $\beta_{2} \mathrm{AR}$ concentration was kept constant. Purified Gs heterotrimer was added at a molar ratio of 3 Gs: $1 \beta_{2}$ AR before reconstitution. (A) The inclusion of Gs in the reconstitution did not alter the orientation of $\beta_{2} \mathrm{AR}$ in vesicles as determined by the susceptibility of reconstituted $\beta_{2}$ AR to PNGase F (see Figure $3 \mathrm{C}$ ). FRET saturation was significantly lower in the presence of Gs compared with $\beta_{2} \mathrm{AR}$ alone (B) or $\beta_{2} \mathrm{AR}$ and Gs with $10 \mu \mathrm{M}$ GTP $\gamma \mathrm{S}$ (C). (D) $\beta_{2}$ AR was labelled on C265 at the cytoplasmic end of TM6 with $\mathrm{mBBr}-\beta_{2} \mathrm{AR}$ and reconstituted with Gs under the same conditions that were used for FRET saturation experiments. Gs induced a decrease in intensity and a $4-\mathrm{nm}$ shift in $\lambda_{\mathrm{MAX}}$ of $\mathrm{mBBr}-\beta_{2} \mathrm{AR}$ relative to the same reconstitution in the presence of GTP $\gamma \mathrm{S}$. A two-way ANOVA was used to compare FRET values for $\beta_{2} A R$, $\beta_{2} \mathrm{AR}+\mathrm{Gs}$ and $\beta_{2} \mathrm{AR}+\mathrm{Gs}+\mathrm{GTP} \gamma \mathrm{S}$ at the different Cy5:Cy3 ratios. A posteriori statistical analysis showed significant decrease in FRET between $\beta_{2} \mathrm{AR}$ and $\beta_{2} \mathrm{AR}+\mathrm{Gs}(P<0.008)$, and a significant increase in FRET between $\beta_{2} \mathrm{AR}+\mathrm{Gs}$ and $\beta_{2} \mathrm{AR}+\mathrm{Gs}+\mathrm{GTP} \gamma \mathrm{S}(P<0.04)$ for all $\mathrm{Cy} 5: \mathrm{Cy} 3$ ratios except 2 and 4 . No statistical differences are found between $\beta_{2} A R$ and $\beta_{2} A R+G s+G T P \gamma S$. 
require integration of information from a variety of different approaches. In an effort to provide additional structural insight into the organization, stability and regulation of GPCR oligomers by ligands, we used FRET to study oligomerization of purified $\beta_{2} \mathrm{AR}$ site specifically labelled with relatively small fluorescent probes and reconstituted into a model lipid bilayer. Our results show that monomeric $\beta_{2}$ ARs oligomerize spontaneously upon reconstitution into lipid bilayers in the absence of other cellular chaperones or scaffold proteins. FRET saturation studies suggest that the oligomers consist of more than two protomers, and are probably tetramers. Agonists have little effect on $\beta_{2}$ AR oligomerization, whereas inverse agonists appear to promote higher-order oligomerization and stabilize the oligomers against dissolution by detergent.

\section{Spontaneous oligomerization of the $\beta_{2} A R$ in model lipid membranes}

In a cell membrane, proteins associate in a complex lipid environment involving mixtures of cholesterol and lipids having different polar groups, alkyl chain lengths and alkyl chain saturation. Moreover, the lipid composition of outer and inner membrane layers is different, and there may be distinct lipid domains that regulate the function of associated membrane proteins (Allen et al, 2007). $\beta_{2}$ AR oligomers have been observed to form during biosynthesis in the endoplasmic reticulum (Salahpour et al, 2004), suggesting that chaperones and other cellular proteins may also be involved in the assembly and/or maintenance of oligomers for some GPCRs. For example, oligomerization of the opioid receptor has been shown to depend on the G protein Gi (Law et al, 2005). Nevertheless, our results show the strong tendency for purified $\beta_{2}$ AR to oligomerize spontaneously in a model lipid bilayer, and suggest that $\beta_{2} \mathrm{AR}$ oligomerization is an intrinsic property of the receptor and does not require other cellular proteins or a specific lipid environment. However, we cannot exclude the possibility that oligomerization in vivo is regulated in some way by cellular proteins or specific lipid environments. It should be noted that rhodopsin, neurotensin receptor 1 and muscarinic receptors have also been observed to oligomerize following reconstitution into synthetic lipid bilayers (Mansoor et al, 2006; Ma et al, 2007; Harding et al, 2009), suggesting that spontaneous oligomerization might be an intrinsic property of Family A GPCRs.

Following purification from insect cell membranes, $\beta_{2}$ ARs exist as pure monomers in detergent solution (Whorton et al, 2007). Our reconstitution experiments use a simple model lipid bilayer composed of DOPC and CHS (DOPC/CHS). In this environment we observe normal ligand binding properties and efficient $G$ protein activation. The high degree of homogenous orientation of receptors in this lipid bilayer model suggests that there must be a non-random mechanism that controls receptor insertion. While the mechanism for this is unknown, preferential orientation has also been observed with reconstitution of rhodopsin, although in this case receptor was oriented preferentially with the N-terminus in the inside of the vesicle (Niu et al, 2002). Isopycnic density centrifugation experiments and EM images (Figure 3) show that reconstitution using size-exclusion chromatography yields a homogenous distribution of receptors into lipid vesicles of an average diameter of $83 \mathrm{~nm}$ and an average surface area of approximately $21600 \mathrm{~nm}^{2}$. Under our recon- stitution conditions, we estimate that there are 50-60 $\beta_{2} \mathrm{AR}$ molecules per vesicle. Based on the crystal structure of the $\beta_{2} \mathrm{AR}$, we can calculate that the surface area occupied by a single receptor is approximately $16 \mathrm{~nm}^{2}$. Therefore, receptors occupy less than $10 \%$ of the surface area of the vesicle, suggesting that the FRET we observe is not the result of nonspecific interactions due to high receptor density. To further exclude the possibility of nonspecific oligomerization, we reconstituted receptors at a 10-fold higher lipid-to-protein ratio and found no significant decrease in FRET efficiency (Figure 5B-D, $P>0.05$ ).

\section{Organization and stability of $\beta_{2} A R$ oligomers}

Our reconstitution system, as well as current cell-based methods, is limited in the ability to precisely define the structure and stoichiometry of oligomers. Nevertheless, recent evidence from resonance energy transfer studies, cysteine cross-linking and fluorescence recovery after photobleaching (FRAP) studies suggest that the D2 dopamine receptor and the $\beta_{2} \mathrm{AR}$ form higher-order oligomers (tetramers or greater) (Guo et al, 2008; Dorsch et al, 2009). Data from FRET studies can provide insight into the orientation of protomers within these oligomers. However, the following facts should be taken into account. First, while Cy3 and Cy5 are small relative to fluorescent and luminescent proteins, they are still large compared with amino acids and have relatively long flexible linkers tethering them to cysteine (Figure 9A). As such, their precise orientation in the protein is not known and has been estimated by computational techniques. Second, both the distance between fluorophores and the orientation of fluorophores influence FRET. The orientation factor becomes a concern for highly constrained fluorophores; however, this probably is not the case here, since the anisotropy values that we observe experimentally for $\mathrm{Cy} 3$ and $\mathrm{Cy} 5$ are similar to those reported for free fluorophores in solution (Kobitski et al, 2007), and these values are not influenced by ligands. Third, as discussed below, the oligomers may be dynamic. While the predominant form may be a tetramer, these may exist in equilibrium with monomers, dimers and higher-order oligomers. Finally, in a tetramer several combinations of donor/acceptor pairs (0 donors, 4 acceptors; 1 donor, 3 acceptors; etc...) are possible. In such a system, the measured FRET signal will be the combination of all the individual energy transfers between every possible donor/acceptor pair, which complicates the analysis of the measured FRET signal, and thus, the estimation of protomer orientation in the tetramer.

Notably, saturation experiments (Figure 6) result in a much simpler system, composed mostly of tetramers with one donor and three acceptors. This system dramatically reduces the number of energy transfer combinations and simplifies the analysis of FRET efficiencies. These values are used to propose possible monomer orientations within the tetramer. In FRET saturations studies, the greatest energy transfer is observed for H8/H8 and smallest for TM6/TM6 (Figure 6B and C). These results are compatible with arrangements of oligomers involving a TM1 interface (Figure 9C) previously described for the D2 dopamine receptor and rhodopsin (Liang et al, 2003; Guo et al, 2008). In contrast, an arrangement that would place TM6/TM6 fluorophores in close proximity (Figure 9B) is not compatible with the lowest FRET efficiency observed for this pair (Figure 6B). 

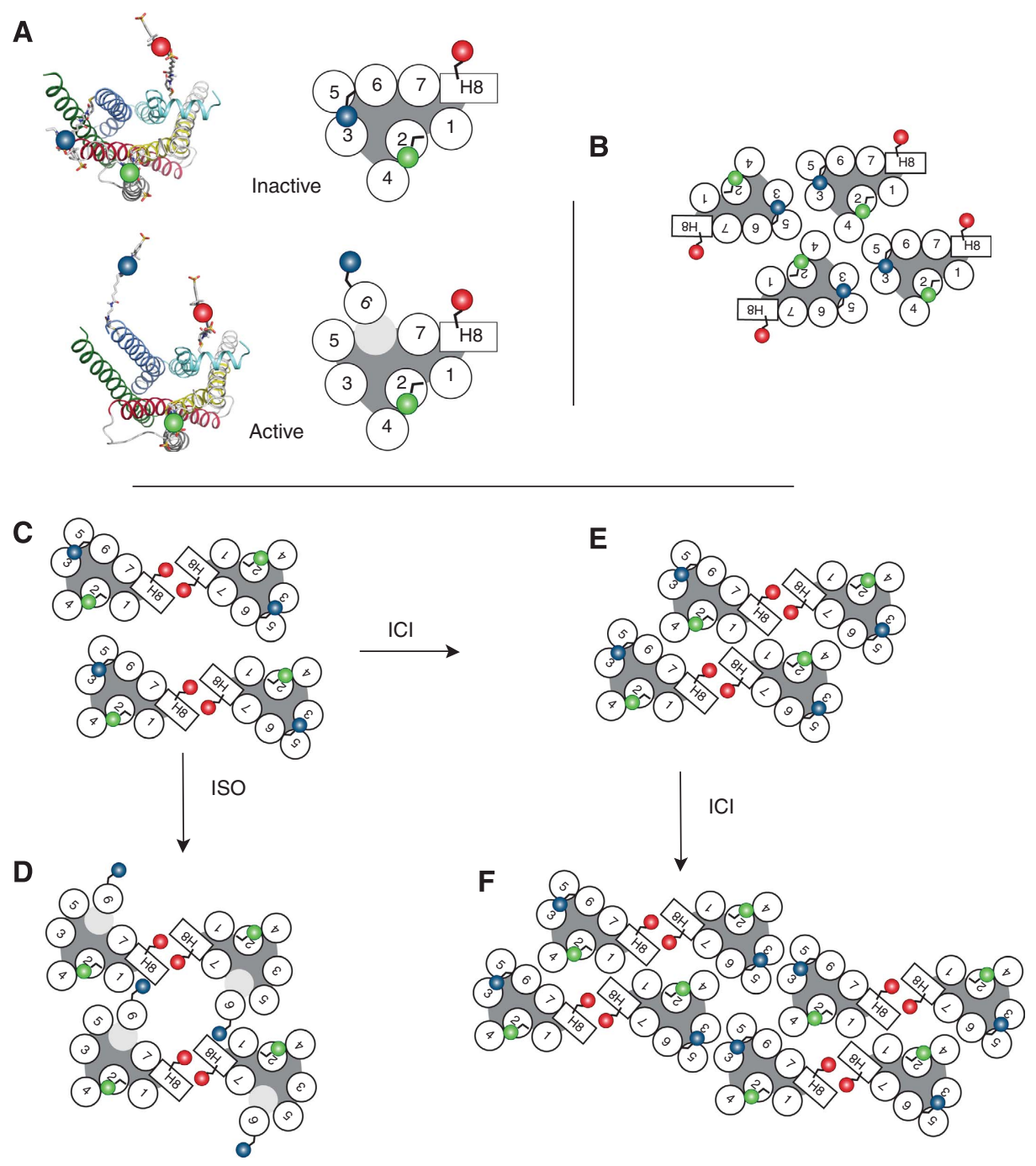

Figure 9 Schematic representation of possible $\beta_{2}$ AR oligomers. (A) Cytoplasmic view of the 3D structure of the $\beta_{2} A R$ (left) and cartoon of this footprint (right), with the centre of mass of Cy3 depicted as spheres: T66C (green), A265C (blue) and R333C (red). TM6 is depicted in the inactive conformation (top) and in the proposed active conformation as observed in the structure of opsin (bottom). (B) Receptor oligomerization involving the surfaces of TMs 4 or/and 5 is not compatible with our FRET results and might sterically prevent movement of TM6. (C) Our FRET results suggest an arrangement of protomers involving the TM1 interface. (D) The movement of the cytoplasmic end of TM6 upon agonist binding repositions the fluorophore outwards in two of the four protomers, and towards H8 in the other two. (E) Treatment with the inverse agonist ICI probably reduces conformational fluctuations responsible for basal activity, increasing the packing of the oligomers. (F) ICI may stabilize higher-order oligomers where TM6 is packed into the core of the oligomer, contributing to increase FRET efficiency and possibly the inactive state of the receptor.

While our FRET saturation experiments best fit a mathematical model for tetramers (Figure 6D), our results are compatible with a dynamic equilibrium where a fraction of $\beta_{2} \mathrm{AR}$ exists as monomers in equilibrium with higher-order oligomers, with the average size of the oligomer being a tetramer. This is in agreement with the observed maximal FRET saturation values of $30-45 \%$ (Figure 6), lower than would be expected for stable tetramers given that $R_{0}$ values for Cy3 and Cy5 range from $37-56 \AA$, depending on the biochemical system under investigation (Mansoor et al, 2006; Massey et al, 2006). Further evidence supporting this dynamic behaviour is the observation that the affinity of interactions between protomers is relatively weak outside of the bilayer environment, as show by the rapid dissociation of protomers upon the addition of a non-ionic detergent (Supplementary Figure 7). Recent FRAP studies provide evidence that D2 dopamine receptors may also exist in a dynamic equilibrium of monomers and oligomers (Fonseca and Lambert, 2009). In these studies, oligomers were only detected by FRAP after receptors formed stable covalent dimers through oxidative cross-linking of cysteines in TM4.

While a $\beta_{2} \mathrm{AR}$ monomer can activate Gs (Whorton et al, 2007), it is not known whether higher-order oligomers facilitate or impair coupling. Oligomers of rhodopsin (Bayburt et al, 2007) and NT1 receptor (White et al, 2007) couple less efficiently to $G$ proteins than monomers. If higher-order oligomers impair coupling, the dynamic character of $\beta_{2} \mathrm{AR}$ oligomers would ensure that a fraction of the $\beta_{2}$ AR would exist as monomers or dimers competent for $G$ protein activation. Under our experimental conditions, the co-reconstitution of Gs with $\beta_{2} \mathrm{AR}$ was associated with a small decrease in FRET saturation that was reversed by GTP $\gamma S$ (Figure 8). This is compatible with $G$ protein coupling shifting the equilibrium to lower-order oligomers. 


\section{Ligand regulation of $\beta_{2} A R$ oligomers}

The effect of agonists on oligomerization has been described for several GPCRs. The results appear to be receptor specific: for some receptors no effect is observed, whereas for others, agonists induce dissociation or association (Angers et al, 2000; Cheng and Miller, 2001; Latif et al, 2002; Zhu et al, 2002; Roess and Smith, 2003; Dorsch et al, 2009). For the $\beta_{2} \mathrm{AR}$, Michelle Bouvier's laboratory reported a small agonistinduced increase in steady-state BRET; however, they concluded that this could be due to a small change in the steadystate oligomers or due to conformational changes in individual protomers (Angers and Bouvier, 2000). In subsequent BRET saturation studies from this laboratory (Mercier et al, 2002) and fluorescence recovery after photobleaching studies from the Bünemann laboratory (Dorsch et al, 2009), no significant agonist-induced effect was observed. Our results with the full agonist (isoproterenol) are in agreement with these cell-based studies. Isoproterenol causes a relatively minor change in intermolecular FRET, with the only significant change occurring in the TM6/H8 FRET pair (Figure 7A and Table II), but no change in FRET saturation (Figure 7B). The results are in agreement with the model depicted in Figure 9C and D where agonists induce a change in protomer conformation, but not oligomerization. We have previously shown significant agonist-induced movement of TM6 (Gether et al, 1997; Ghanouni et al, 2001a, b; Yao et al, 2006) consistent with relatively large conformational changes observed in rhodopsin by DEER spectroscopy (Altenbach et al, 2008), and from the crystal structure of opsin (Park et al, 2008; Scheerer et al, 2008). Assuming a tetramer, the movement of the cytoplasmic end of TM6 away from TM3 (Park et al, 2008) (Figure 9A) locates the fluorophore attached to TM6 towards the periphery in two of the four protomers, and towards $\mathrm{H} 8$ in the other two (Figure 9D). Thus, the symmetric movement of TM6 in the tetramer, inwards and outwards, explains the minor changes in intermolecular FRET of TM6/TM6 observed upon agonist binding. In addition, the inward movement of TM6 towards $\mathrm{H} 8$ is compatible with the changes occurring in the TM6/H8 FRET pairs. Therefore, protomer packing does not appear to interfere with conformational changes involving TM6. In agreement with this, agonist-induced movement of the cytoplasmic end of TM6, as detected by an environmentally sensitive fluorophore covalently bound to C265, is similar for $\beta_{2} \mathrm{AR}$ monomers (reconstituted into HDL particles) and oligomers (reconstituted into phospholipids vesicles) (Supplementary Figure 8).

We were surprised to see that the most dramatic changes in intermolecular FRET were observed on exposure to the inverse agonist ICI. Most notable are increases in FRET for TM6/TM6 and ICL1/H8 (Table II and Figure 7A). Fluorescence studies on monomeric $\beta_{2} \mathrm{AR}$ may provide us with the link between the effect of an inverse agonist on the structure of the monomer and the process of oligomerization. We have previously shown that ICI does not induce major rearrangements in the structure of the monomer, but may reduce normal conformational fluctuations responsible for basal activity (Yao et al, 2006, 2009). We speculate that this inherent flexibility may interfere with higher-order packing of the oligomers. Thus, the more constrained structure of the inverse agonist-bound receptor may be more compatible with closer packing of protomers within a tetramer (Figure 9E), a higher-order packing (Figure 9F) or more stable $\beta_{2} \mathrm{AR}$ oligomers with fewer monomers. It has been observed that oligomers of rhodopsin (Bayburt et al, 2007) and NT1 receptor (White et al, 2007) couple less efficiently to G proteins than monomers; therefore, higher-order packing induced by the inverse agonist may restrict access of receptor to $G$ protein. However, this higher-order packing is not required for the inverse agonist effect, as an inverse agonist can efficiently prevent coupling of monomeric $\beta_{2} \mathrm{AR}$ to Gs (Yao et al, 2009). It is likely that a combination of all three effects is responsible for the ICI-induced FRET changes. The increased stability of oligomers against dissociation by detergent in the presence of ICI (Supplementary Figure 7) is in agreement with closer packing of protomers, while FRET saturation (Figure 7B and Supplementary Figure 5) and cross-linking experiments (Figure 7C and Supplementary Figure 6) are in agreement with higher-order oligomers. Our results are consistent with a rearrangement of the oligomerization interfaces that has been observed for the dopamine D2 receptor upon inverse agonist binding (Guo et $a l, 2005$ ), and the observation of higher-order packing of the inactive state of rhodopsin in rod outer segment membranes (Liang et al, 2003). The functional consequence of this higher-order oligomerization is not known, but could impair coupling of the $\beta_{2} \mathrm{AR}$ to $\mathrm{Gs}$, or be involved in the coupling of the $\beta_{2} \mathrm{AR}$ to other signalling pathways. Interestingly, both ICI and carvedilol have been shown to activate MAPK through a $\mathrm{G}$ protein-independent, arrestin-dependent signalling pathway (Galandrin and Bouvier, 2006; Wisler et al, 2007). The dramatic effects of ICI on oligomerization might be expected to influence ICI binding affinity or cooperativity; however, no differences in ICI binding properties were observed between $\beta_{2} \mathrm{AR}$ monomers (reconstituted into HDL particles) and oligomers (reconstituted into phospholipids vesicles) (data not shown).

In conclusion, we find that the $\beta_{2} \mathrm{AR}$ is capable of forming specifically oriented multimeric assemblies in a model lipid bilayer in the absence of other cellular proteins, complementing previous studies of Family A GPCRs. Although we cannot determine the oligomeric interfaces with precision, our results are compatible with models proposed for several other Family A GPCRs, where oligomerization involves primarily the TM1/H8 interface. Most unexpected was the observation that inverse agonists promoted higher-order $\beta_{2} \mathrm{AR}$ oligomerization. This may alter access to other signalling proteins, providing insight into the ability of inverse agonists to inhibit basal G protein signalling or in promoting $G$ protein-independent activation of MAPK pathways. These results suggest a potential structural link between the stabilizing effects of inverse agonists on $\beta_{2} \mathrm{AR}$ monomers and the assembly of oligomers in lipid bilayers.

\section{Materials and methods}

\section{Materials}

Cy3-maleimide and Cy5-maleimide were both obtained from Amersham Biosciences. $\left[{ }^{3} \mathrm{H}\right]$-DHA and $\left[{ }^{35} \mathrm{~S}\right]$-GTP $\gamma \mathrm{S}$ were purchased from Amersham and Perkin Elmer, respectively. All drugs tested were purchased from Sigma. The Bis(NHS) $\mathrm{PEO}_{5}$ homobifunctional cross-linker and NHS-PEO${ }_{4}$-Biotin were purchased from Pierce.

\section{Engineering of single-cysteine $\beta_{2} A R$ mutants}

Site-directed mutagenesis of the $\beta_{2}$ AR was performed by using the human $\beta_{2}$ AR cDNA containing a FLAG epitope at the N-terminus as 
well as a six histidine tag at the $\mathrm{C}$-terminus. The five reactive cysteines (out of 13 native cysteines) in the $\beta_{2} \mathrm{AR}$ were mutated as follows: C77V, C265A, C327S, C378A and C406A to generate a $\Delta 5$ background (Gether et al, 1997). Mutations for the three singlereactive cysteine constructs (T66C, A265C and R333C all in $\Delta 5$ ) in these studies were carried out by PCR mutagenesis with Pfu polymerase (Stratagene, La Jolla, CA). The mutated cDNA was then digested with appropriate enzymes and cloned into the pFastBac1 (Invitrogen) vector. All constructs were confirmed by restriction enzyme analysis and DNA sequencing.

\section{Expression and purification of $\beta_{2} A R$ from Sf9 insect cells}

Sf9 insect cells were grown at $27^{\circ} \mathrm{C}$ in suspension cultures in ESF921 medium (Expression Systems, CA) supplemented with $0.5 \mathrm{mg}$ / $\mathrm{ml}$ gentamicin. The Bac-to-Bac Baculovirus Expression System (Invitrogen) was used for generating baculovirus for each of the $\beta_{2} \mathrm{AR}$ constructs. $\beta_{2} \mathrm{AR}$ expression was accomplished by infecting Sf9 cells at a density of $\sim 3 \times 10^{6}$ cells $/ \mathrm{ml}$ for $\sim 48 \mathrm{~h}$. Cells now expressing receptor, as assessed by immunofluorescence, were harvested by centrifugation $(15 \mathrm{~min}$ at $5000 \mathrm{~g}$ ). Cell pellets were stored at $-80^{\circ} \mathrm{C}$ prior to purification. $\beta_{2} \mathrm{AR}$ from Sf 9 cells was purified using a three-step purification procedure involving $\mathrm{M} 1 \mathrm{anti}-$ FLAG column, followed by alprenolol-Sepharose affinity column and a second M1 anti-FLAG column as described previously (Swaminath et al, 2005; Granier et al, 2007). Saturation binding of the antagonist $\left[{ }^{3} \mathrm{H}\right]$-DHA was used to determine the concentration of functional purified $\beta_{2} \mathrm{AR}$. Detailed protocols are found in Supplementary data.

\section{Lipid preparation}

DOPC 18:1 phospholipid (Avanti Polar Lipids Inc.) and CHS (Steraloids, Inc.) were mixed and dissolved in chloroform to form a stock solution of lipids at a concentration of 20 and $10 \mathrm{mg} / \mathrm{ml}$, respectively. DOPC and cholesterol were added to a glass vial, with DOPC at a 10 -fold molar excess, and chloroform was evaporated under a fine stream of argon. The lipids were then further dried under vacuum for $1 \mathrm{~h}$. The lipids were resuspended in Buffer $\mathrm{G}$ (20 mM HEPES, $100 \mathrm{mM} \mathrm{NaCl}, 1 \%$ octylglucoside, $\mathrm{pH}$ 7.5), vortexed and sonicated for $1 \mathrm{~h}$ in an ice water bath. The lipid mixture was stored at $-80^{\circ} \mathrm{C}$.

Fluorescence labelling and reconstitution of purified receptors Purified $\beta_{2}$ ARs were labelled with two equivalents of either Cy3maleimide or Cy5-maleimide (Amersham Biosciences) for $15 \mathrm{~min}$ at $4{ }^{\circ} \mathrm{C}$. Labelling reactions were quenched by adding a final of $1 \mathrm{mM}$ L-cysteine.

$\beta_{2} \mathrm{AR}$ was reconstituted as described previously (Swaminath et al, 2005). Briefly, for each mutant generated, 300- $\mu$ l samples were prepared containing the following receptors for reconstitution: either Cy3 $-\beta_{2}$ AR alone, Cy5- $\beta_{2}$ AR alone or both $C y 3-\beta_{2} A R$ and Cy5 $-\beta_{2}$ AR. The amount of both labelled receptors and lipids used for reconstitution varied depending on the lipid-to-receptor ratio. Either 1000:1 (mol lipid:mol receptor) or 10 000:1 (mol lipid:mol receptor) conditions were used. The lipid/receptor mixture, plus reconstitution buffer to $300 \mu \mathrm{l}$, was mixed and placed on ice for $2 \mathrm{~h}$. Vesicles were allowed to form by removing detergent on a

\section{References}

Allen JA, Halverson-Tamboli RA, Rasenick MM (2007) Lipid raft microdomains and neurotransmitter signalling. Nat Rev Neurosci 8: $128-140$

Altenbach C, Kusnetzow AK, Ernst OP, Hofmann KP, Hubbell WL (2008) High-resolution distance mapping in rhodopsin reveals the pattern of helix movement due to activation. Proc Natl Acad Sci USA 105: 7439-7444

Angers S, Bouvier M (2000) Reply: beyond receptor dimerization. Trends Pharmacol Sci 21: 326

Angers S, Salahpour A, Joly E, Hilairet S, Chelsky D, Dennis M, Bouvier M (2000) Detection of beta 2-adrenergic receptor dimerization in living cells using bioluminescence resonance energy transfer (BRET). Proc Natl Acad Sci USA 97: 3684-3689

Bayburt TH, Leitz AJ, Xie G, Oprian DD, Sligar SG (2007) Transducin activation by nanoscale lipid bilayers containing one and two rhodopsins. J Biol Chem 282: 14875-14881
Sephadex G-50 (fine) column $(25 \times 0.8 \mathrm{~cm})$ using reconstitution buffer (20 mM HEPES, $100 \mathrm{mM} \mathrm{NaCl}$, pH 7.5).

To assess the proportion of receptors incorporating into vesicles, we performed discontinuous sucrose gradients as described previously for rhodopsin (Mansoor et al, 2006) (see Supplementary data).

The number of fluorophore molecules per reconstituted receptor was calculated by using the maximum absorbance of the donor- or acceptor-labelled receptor. The number of donor or acceptor fluorophores per $\beta_{2} \mathrm{AR}$ ranged between different preps from 0.4 to 0.8 for all three constructs (Supplementary Table 1).

\section{Fluorescence spectroscopy}

Experiments were performed at $25^{\circ} \mathrm{C}$ with a SPEX FluoroMax-3 spectrofluorometer (excitation and emission bandpass of $2 \mathrm{~nm}$, $\mathrm{S} / \mathrm{R}$ acquisition mode). The final concentration of $\beta_{2} \mathrm{AR}$ used for spectroscopy was typically $\sim 20 \mathrm{nM}$.

For FRET experiments, spectra were taken from receptors labelled with donor $(\mathrm{Cy} 3)$ and reconstituted together with receptors labelled with acceptor (Cy5) at the various cysteine mutants generated. Spectra of receptors labelled with only the acceptor fluorophore and reconstituted alone were also taken. For each type of receptor, two types of emission scans were acquired. The first emission scan (donor scan) acquired used the excitation maximum for the donor fluorophore Cy3 $\left(\lambda_{\text {ex }}=550 \mathrm{~nm}\right)$. The second emission scan (acceptor scan) used the excitation maximum for the acceptor fluorophore Cy5 $\left(\lambda_{\text {ex }}=649 \mathrm{~nm}\right)$. For testing the effects of $\beta_{2} \mathrm{AR}$ ligands, samples \pm drug were mixed and incubated $20 \mathrm{~min}$ at RT. Three separate samples were used for testing each type of drug and individual spectra were acquired and averaged. Removal of acceptor bleed-through and correction of any drug-induced acceptor fluorescence intensity changes were carried out and described in detail previously (Granier et $a l, 2007$ ) and are present in Supplementary data.

\section{Supplementary data}

Supplementary data are available at The EMBO Journal Online (http://www.embojournal.org).

\section{Acknowledgements}

We thank the Stanford University Cell Sciences Imaging Facility, in particular, John Perino, for assistance in obtaining EM images of lipid vesicles. We thank David Farrens, Sébastien Granier and Aaron Shafer for advice on the design and interpretation of experiments. This work was supported by NIH Grant GM007276 to JJF, RO1GM068603 to RKK and NS28471 to BKK, as well as the Mather Charitable Foundation to BK. LP is supported by ISCIII Grant RD07/ 0067/0008. XD is supported by Ministerio de Ciencia e Innovación, Government of Spain, through the Ramón y Cajal program.

\section{Conflict of interest}

The authors declare that they have no conflict of interest.
Brett M, Findlay JB (1979) Investigation of the organization of rhodopsin in the sheep photoreceptor membrane by using cross-linking reagents. Biochem J 177: 215-223

Chabre M, le Maire M (2005) Monomeric G-protein-coupled receptor as a functional unit. Biochemistry 44: 9395-9403

Cheng ZJ, Miller LJ (2001) Agonist-dependent dissociation of oligomeric complexes of $\mathrm{G}$ protein-coupled cholecystokinin receptors demonstrated in living cells using bioluminescence resonance energy transfer. J Biol Chem 276: 48040-48047

Cherezov V, Rosenbaum DM, Hanson MA, Rasmussen SG, Thian FS, Kobilka TS, Choi HJ, Kuhn P, Weis WI, Kobilka BK, Stevens RC (2007) High-resolution crystal structure of an engineered human beta2adrenergic G protein-coupled receptor. Science 318: 1258-1265

Dorsch S, Klotz KN, Engelhardt S, Lohse MJ, Bunemann M (2009) Analysis of receptor oligomerization by FRAP microscopy. Nat Methods 6: 225-230 
Downer NW (1985) Cross-linking of dark-adapted frog photoreceptor disk membranes. Evidence for monomeric rhodopsin. Biophys J 47: 285-293

Ernst OP, Gramse V, Kolbe M, Hofmann KP, Heck M (2007) Monomeric G protein-coupled receptor rhodopsin in solution activates its $G$ protein transducin at the diffusion limit. Proc Natl Acad Sci USA 104: 10859-10864

Fonseca JM, Lambert NA (2009) Instability of a class A GPCR oligomer interface. Mol Pharmacol 75: 1296-1299

Fung BK, Hurley JB, Stryer L (1981) Flow of information in the lighttriggered cyclic nucleotide cascade of vision. Proc Natl Acad Sci USA 78: 152-156

Galandrin S, Bouvier M (2006) Distinct signaling profiles of beta1 and beta 2 adrenergic receptor ligands toward adenylyl cyclase and mitogen-activated protein kinase reveals the pluridimensionality of efficacy. Mol Pharmacol 70: 1575-1584

Galvez T, Duthey B, Kniazeff J, Blahos J, Rovelli G, Bettler B, Prezeau L, Pin JP (2001) Allosteric interactions between GB1 and GB2 subunits are required for optimal GABAB receptor function. EMBO J 20: 2152-2159

Gether U, Lin S, Ghanouni P, Ballesteros JA, Weinstein H, Kobilka BK (1997) Agonists induce conformational changes in transmembrane domains III and VI of the beta2 adrenoceptor. EMBO J 16: 6737-6747

Ghanouni P, Gryczynski Z, Steenhuis JJ, Lee TW, Farrens DL, Lakowicz JR, Kobilka BK (2001a) Functionally different agonists induce distinct conformations in the $\mathrm{G}$ protein coupling domain of the beta 2 adrenergic receptor. J Biol Chem 276: 24433-24436

Ghanouni P, Steenhuis JJ, Farrens DL, Kobilka BK (2001b) Agonistinduced conformational changes in the G-protein-coupling domain of the beta 2 adrenergic receptor. Proc Natl Acad Sci USA 98: 5997-6002

Gines S, Hillion J, Torvinen M, Le Crom S, Casado V, Canela EI, Rondin S, Lew JY, Watson S, Zoli M, Agnati LF, Verniera P, Lluis C, Ferre S, Fuxe K, Franco R (2000) Dopamine D1 and adenosine A1 receptors form functionally interacting heteromeric complexes. Proc Natl Acad Sci USA 97: 8606-8611

Gonzalez-Maeso J, Ang RL, Yuen T, Chan P, Weisstaub NV, LopezGimenez JF, Zhou M, Okawa Y, Callado LF, Milligan G, Gingrich JA, Filizola M, Meana JJ, Sealfon SC (2008) Identification of a serotonin/glutamate receptor complex implicated in psychosis. Nature 452: 93-97

Granier S, Kim S, Shafer AM, Ratnala VR, Fung JJ, Zare RN, Kobilka B (2007) Structure and conformational changes in the C-terminal domain of the beta2-adrenoceptor: insights from fluorescence resonance energy transfer studies. $\mathrm{J}$ Biol Chem 282: 13895-13905

Guo W, Shi L, Filizola M, Weinstein H, Javitch JA (2005) Crosstalk in $\mathrm{G}$ protein-coupled receptors: changes at the transmembrane homodimer interface determine activation. Proc Natl Acad Sci USA 102: 17495-17500

Guo W, Shi L, Javitch JA (2003) The fourth transmembrane segment forms the interface of the dopamine D2 receptor homodimer. J Biol Chem 278: 4385-4388

Guo W, Urizar E, Kralikova M, Mobarec JC, Shi L, Filizola M, Javitch JA (2008) Dopamine D2 receptors form higher order oligomers at physiological expression levels. EMBO J 27: 2293-2304

Harding PJ, Attrill H, Boehringer J, Ross S, Wadhams GH, Smith E, Armitage JP, Watts A (2009) Constitutive dimerization of the g-protein coupled receptor, neurotensin receptor 1, reconstituted into phospholipid bilayers. Biophys J 96: 964-973

Harikumar KG, Happs RM, Miller LJ (2008) Dimerization in the absence of higher-order oligomerization of the $G$ protein-coupled secretin receptor. Biochim Biophys Acta 1778: 2555-2563

Hebert TE, Moffett S, Morello JP, Loisel TP, Bichet DG, Barret C, Bouvier M (1996) A peptide derived from a beta2-adrenergic receptor transmembrane domain inhibits both receptor dimerization and activation. $J$ Biol Chem 271: 16384-16392

Hill SJ (2006) G-protein-coupled receptors: past, present and future. Br J Pharmacol 147 (Suppl 1): S27-S37

James JR, Oliveira MI, Carmo AM, Iaboni A, Davis SJ (2006) A rigorous experimental framework for detecting protein oligomerization using bioluminescence resonance energy transfer. Nat Methods 3: 1001-1006

Jones KA, Borowsky B, Tamm JA, Craig DA, Durkin MM, Dai M, Yao WJ, Johnson M, Gunwaldsen C, Huang LY, Tang C, Shen Q, Salon
JA, Morse K, Laz T, Smith KE, Nagarathnam D, Noble SA, Branchek TA, Gerald C (1998) GABA(B) receptors function as a heteromeric assembly of the subunits GABA(B)R1 and GABA(B)R2. Nature 396: 674-679

Jordan BA, Devi LA (1999) G-protein-coupled receptor heterodimerization modulates receptor function. Nature 399: 697-700

Klco JM, Lassere TB, Baranski TJ (2003) C5a receptor oligomerization. I. Disulfide trapping reveals oligomers and potential contact surfaces in a G protein-coupled receptor. J Biol Chem 278: $35345-35353$

Kobitski AY, Nierth A, Helm M, Jaschke A, Nienhaus GU (2007) $\mathrm{Mg} 2$ +-dependent folding of a Diels-Alderase ribozyme probed by single-molecule FRET analysis. Nucleic Acids Res 35: 2047-2059

Latif R, Graves P, Davies TF (2002) Ligand-dependent inhibition of oligomerization at the human thyrotropin receptor. $J$ Biol Chem 277: 45059-45067

Law PY, Erickson-Herbrandson LJ, Zha QQ, Solberg J, Chu J, Sarre A, Loh HH (2005) Heterodimerization of mu- and delta-opioid receptors occurs at the cell surface only and requires receptor-G protein interactions. J Biol Chem 280: 11152-11164

Liang Y, Fotiadis D, Filipek S, Saperstein DA, Palczewski K, Engel A (2003) Organization of the $\mathrm{G}$ protein-coupled receptors rhodopsin and opsin in native membranes. J Biol Chem 278: 21655-21662

Ma AW, Redka DS, Pisterzi LF, Angers S, Wells JW (2007) Recovery of oligomers and cooperativity when monomers of the M2 muscarinic cholinergic receptor are reconstituted into phospholipid vesicles. Biochemistry 46: 7907-7927

Mansoor SE, Palczewski K, Farrens DL (2006) Rhodopsin selfassociates in asolectin liposomes. Proc Natl Acad Sci USA 103 3060-3065

Margeta-Mitrovic M, Jan YN, Jan LY (2000) A trafficking checkpoint controls GABA(B) receptor heterodimerization. Neuron 27: 97-106

Massey M, Algar WR, Krull UJ (2006) Fluorescence resonance energy transfer (FRET) for DNA biosensors: FRET pairs and Forster distances for various dye-DNA conjugates. Anal Chim Acta 568: 181-189

Medina R, Perdomo D, Bubis J (2004) The hydrodynamic properties of dark- and light-activated states of n-dodecyl beta-D-maltosidesolubilized bovine rhodopsin support the dimeric structure of both conformations. J Biol Chem 279: 39565-39573

Mellado M, Rodriguez-Frade JM, Vila-Coro AJ, Fernandez S, Martin de Ana A, Jones DR, Toran JL, Martinez AC (2001) Chemokine receptor homo- or heterodimerization activates distinct signaling pathways. EMBO J 20: 2497-2507

Mercier JF, Salahpour A, Angers S, Breit A, Bouvier M (2002) Quantitative assessment of beta 1- and beta 2-adrenergic receptor homo- and heterodimerization by bioluminescence resonance energy transfer. J Biol Chem 277: 44925-44931

Milligan G, Bouvier M (2005) Methods to monitor the quaternary structure of G protein-coupled receptors. FEBS J 272: 2914-2925

Niu L, Kim JM, Khorana HG (2002) Structure and function in rhodopsin: asymmetric reconstitution of rhodopsin in liposomes. Proc Natl Acad Sci USA 99: 13409-13412

Park JH, Scheerer P, Hofmann KP, Choe HW, Ernst OP (2008) Crystal structure of the ligand-free G-protein-coupled receptor opsin. Nature 454: 183-187

Pin JP, Kniazeff J, Liu J, Binet V, Goudet C, Rondard P, Prezeau L (2005) Allosteric functioning of dimeric class C G-protein-coupled receptors. FEBS J 272: 2947-2955

Rasmussen SG, Choi HJ, Rosenbaum DM, Kobilka TS, Thian FS, Edwards PC, Burghammer M, Ratnala VR, Sanishvili R, Fischetti RF, Schertler GF, Weis WI, Kobilka BK (2007) Crystal structure of the human beta2 adrenergic G-protein-coupled receptor. Nature 450: $383-387$

Rocheville M, Lange DC, Kumar U, Patel SC, Patel RC, Patel YC (2000) Receptors for dopamine and somatostatin: formation of hetero-oligomers with enhanced functional activity. Science 288: $154-157$

Roess DA, Smith SM (2003) Self-association and raft localization of functional luteinizing hormone receptors. Biol Reprod 69: $1765-1770$

Rosenbaum DM, Cherezov V, Hanson MA, Rasmussen SG, Thian FS, Kobilka TS, Choi HJ, Yao XJ, Weis WI, Stevens RC, Kobilka BK (2007) GPCR engineering yields high-resolution structural insights into beta2-adrenergic receptor function. Science 318: $1266-1273$ 
Salahpour A, Angers S, Mercier JF, Lagace M, Marullo S, Bouvier M (2004) Homodimerization of the beta2-adrenergic receptor as a prerequisite for cell surface targeting. J Biol Chem 279: 33390-33397

Scheerer P, Park JH, Hildebrand PW, Kim YJ, Krauss N, Choe HW, Hofmann KP, Ernst OP (2008) Crystal structure of opsin in its G-protein-interacting conformation. Nature 455: 497-502

Swaminath G, Deupi X, Lee TW, Zhu W, Thian FS, Kobilka TS, Kobilka B (2005) Probing the beta2 adrenoceptor binding site with catechol reveals differences in binding and activation by agonists and partial agonists. J Biol Chem 280: 22165-22171

Veatch W, Stryer L (1977) The dimeric nature of the gramicidin A transmembrane channel: conductance and fluorescence energy transfer studies of hybrid channels. J Mol Biol 113: 89-102

Vilardaga JP, Nikolaev VO, Lorenz K, Ferrandon S, Zhuang Z, Lohse MJ (2008) Conformational cross-talk between alpha2A-adrenergic and mu-opioid receptors controls cell signaling. Nat Chem Biol 4: 126-131

White JF, Grodnitzky J, Louis JM, Trinh LB, Shiloach J, Gutierrez J, Northup JK, Grisshammer R (2007) Dimerization of the class A G protein-coupled neurotensin receptor NTS1 alters G protein interaction. Proc Natl Acad Sci USA 104: 12199-12204

Whorton MR, Bokoch MP, Rasmussen SG, Huang B, Zare RN, Kobilka B, Sunahara RK (2007) A monomeric G protein-coupled receptor isolated in a high-density lipoprotein particle efficiently activates its G protein. Proc Natl Acad Sci USA 104: 7682-7687

Wisler JW, DeWire SM, Whalen EJ, Violin JD, Drake MT, Ahn S, Shenoy SK, Lefkowitz RJ (2007) A unique mechanism of betablocker action: carvedilol stimulates beta-arrestin signaling. Proc Natl Acad Sci USA 104: 16657-16662

Yao X, Parnot C, Deupi X, Ratnala VR, Swaminath G, Farrens D, Kobilka B (2006) Coupling ligand structure to specific conformational switches in the beta2-adrenoceptor. Nat Chem Biol 2: 417-422

Yao X, Ruiz GV, Whoron MR, Rasmussen SGG, DeVree BT, Deupi X, Sunahara RK, Kobilka BK (2009) The effect of ligand efficacy on the formation and stability of a GPCR-G protein complex. Proc Natl Acad Sci USA 106: 9501-9506

Zhu CC, Cook LB, Hinkle PM (2002) Dimerization and phosphorylation of thyrotropin-releasing hormone receptors are modulated by agonist stimulation. J Biol Chem 277: 28228-28237

(c) The EMBO Journal is published by Nature Molecular Biology Organization. This article is licensed under a Creative Commons Attribution-NoncommercialShare Alike 3.0 Licence. [http://creativecommons.org/ licenses/by-nc-sa/3.0/] 